\title{
Tumor-Promoting Activity of Long Noncoding RNA LINC00466 in Lung Adenocarcinoma via miR-144-Regulated HOXA10 Axis
}

Tiangang $\mathrm{Ma},{ }^{*}$ Yanbing $\mathrm{Hu},{ }^{\dagger}$ Yingxue Guo, ${ }^{\ddagger}$ and Bingdi Yan*

From the Departments of Respiratory, ${ }^{*}$ Ultrasound,${ }^{\dagger}$ and Clinical Laboratory, ${ }^{\ddagger}$ Second Hospital Affiliated to Jilin University, Changchun, PR China

Accepted for publication

June 18, 2019.

Address correspondence to Yingxue Guo, M.M., Department of Clinical Laboratory, or Bingdi Yan, M.M., Department of Respiratory, Second Hospital Affiliated to Jilin University, No. 218, Ziqiang St, Nanguan District, Changchun 130021, Jilin Province, PR China. Email:40110850@qq.com or 13504402490@163.com.

\begin{abstract}
Previous investigations have implicated long noncoding RNAs in lung adenocarcinoma, which is an aggressive disease with poor prognosis and high mortality. Through the alteration of lung adenocarcinoma-related long noncoding RNA and miRNA based on microarray analysis, our aim was to understand the role of LINCO0466 and miR-144 in lung adenocarcinoma progression. The relationship among LINC00466, miR-144, and HOXA10 was also verified. Moreover, to examine whether the LINC00466/miR-144/HOXA10 axis contributed to the cellular processes in lung adenocarcinoma, A549 and XWLC-05 cells were transduced with siRNA LINCO0466, siRNA HOXA10, or miR-144 mimic plasmids. Highly expressed LINC00466 and HOXA10 and lowly expressed miR-144 were eventually revealed in lung adenocarcinoma tissues. HOXA10 was down-regulated in response to the overexpression of miR-144, whereas inhibition of LINCO0466 decreased its binding to miR-144, thereby up-regulating miR-144, which, in turn, halted the lung adenocarcinoma progression. LINC00466 silencing or miR-144 upregulation exerted an inhibitory role in the tumorigenicity, invasion, migration, and proliferation, and it also promoted apoptosis of lung adenocarcinoma cells. Furthermore, tumor formation was inhibited by knockdown of LINCO0466 or overexpression of miR-144. Taken together, LINCO0466 could restrain the miR-144 expression to up-regulate $H O X A 10$ and, therefore, promote lung adenocarcinoma. (Am J Pathol 2019, 189: 2154-2170; https://doi.org/10.1016/j.ajpath.2019.06.014)
\end{abstract}

Lung cancer remains one of the top causes of worldwide mortality. To illustrate, $>1.2$ million new cases are diagnosed each year. ${ }^{1}$ Lung adenocarcinoma represents a type of non-small-cell lung carcinoma. This is known as a form of lung cancer with specific etiology, molecular changes, and morphologic features. ${ }^{2,3}$ Cigarette use is one major risk factor for lung adenocarcinoma, although approximately $10 \%$ to $15 \%$ of lung adenocarcinomas are diagnosed in individuals without a history of smoking, ${ }^{4}$ which may be caused by environmental exposures and genetic susceptibility. ${ }^{5,6}$ Although progress has been made in treating lung cancer, the overall survival rate continues to be relatively low. The major issues in lung cancer treatment include fast onset of chemoresistance and predominantly late diagnosis.

Long noncoding RNAs (lncRNAs) may contribute to the pathogenesis of different cancers, including lung adenocarcinoma. ${ }^{8}$ Genes related to different cell proliferation and developmental pathways in lung adenocarcinoma were tracked by $\mathrm{CpG}$ sites; some of them were related to long noncoding RNAs, including LINC00466, indicating a potential correlation between lung adenocarcinoma and LINC00466. LINC00466, as one pivot regulator of autism spectrum disorder, is involved in different developmental, neural, or brain-related biological progress. ${ }^{10}$ Many miRNAs, including $m i R-212, m i R-451$, and $m i R-221$, were involved in lung cancer through different cellular processes. $^{11-13}$ miR-144 exerts a fundamental function in different carcinomas (eg, colorectal cancer, gastric cancer, and hepatocellular carcinoma). ${ }^{14-16}$ miR-144 also correlates with lung cancer progression, which is down-regulated in

Supported by Jilin Provincial Science and Technology Program Excellent Youth Talents Fund grant 20180520137JH.

Disclosures: None declared. 
Table 1 Primer Sequence for RT-qPCR

\begin{tabular}{ll}
\hline Primer & Sequence \\
\hline LINC00466 & F: 5'-AGCCCTTCCGTCTTGTTACG-3' \\
& R: 5'-GCTTCCCAACTGCAGGTTTC-3' \\
miR-144 & F: 5'-GCTGGGATATCATCATATACTG-3' \\
& R: 5'-CGGACTAGTACATCATCTATACTG-3' \\
H0XA10 & F: 5'-GCCCCTTCCGAGAGCAGCAAAG-3' \\
& R: 5'-AGGTGGACGCTGCGGCTAATCTCTA-3' \\
GAPDH & F: 5'-CGTATTGGGCGCCTGGTCACCAG-3' \\
U6 & R: 5'-GTTGTCATGGATGACCTTGGCCAG-3' \\
& F: 5'-CTCGCTTCGGCAGCACA-3' \\
& R: 5'-AACGCTTCACGAATTTGCGT-3'
\end{tabular}

F, forward; GAPDH, glyceraldehyde-3-phosphate dehydrogenase; HOXA10, homeobox A10; R, reverse; RT-qPCR, quantitative RT-PCR.

highly polluted regions of non-small-cell lung carcinoma. ${ }^{17}$ Homeobox A10 (HOXA10), a member of the HOX family, has been highlighted to regulate cell differentiation, maturation, development, and proliferation. HOXA10 has been implicated in cancers, including gastric cancer, prostate carcinoma, and colorectal cancer. ${ }^{18-20}$ An increasing amount of evidence proposes that HOXA10 could be targeted by different miRNAs to regulate cancer development. ${ }^{20-22}$ Our aim was to study the role of HOXA1O and LINCO0466 in lung adenocarcinoma.

\section{Materials and Methods}

\section{Ethics Statement}

The Animal Ethics Committee of the Second Hospital Affiliated to Jilin University (Changchun, China) approved the experimentation and animal use in this study. All efforts were made in a humane way to relieve suffering of the animals.

\section{Lung Adenocarcinoma Cell Line Selection}

Lung adenocarcinoma cell lines (GLC-82, H1299, XWLC05, A549, and SPCA-1) and normal lung cell line HBE were purchased from the cell bank of the Institute of Biochemistry and Cell Biology, Chinese Academy of Sciences (Shanghai, China). The five lung adenocarcinoma cell lines were cultured in Dulbecco's modified Eagle's medium containing $10 \%$ fetal bovine serum (FBS; GIBCO BRL, Grand Island, NY). The normal lung cell line HBE was cultured in RPMI 1640 culture medium containing 10\% neonatal FBS (Yuanmu Biotech Co, Ltd, Shanghai,

A

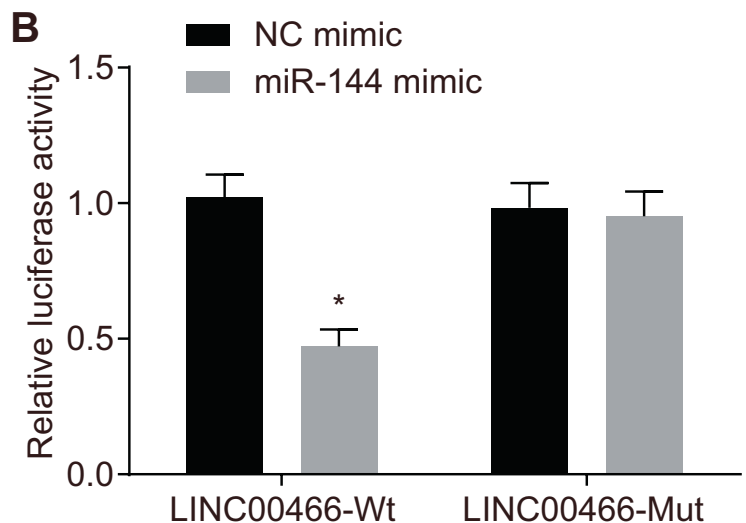

C

3' GGGGGTGCCCGGCTGTCTC TCTTCTGTGTGTCT 5' CCCCCAGTAAG CTACAAAGGGATTACCAGCGTT

\begin{tabular}{|c|c|c|c|c|c|c|c|}
\hline & $\begin{array}{l}\text { Predicted consequential pairing of target region (top) } \\
\text { and miRNA (bottom) }\end{array}$ & Site type & $\begin{array}{l}\text { Context++ } \\
\text { score }\end{array}$ & $\begin{array}{l}\text { Context++ } \\
\text { score } \\
\text { percentile }\end{array}$ & $\begin{array}{l}\text { Weighted } \\
\text { context+++ } \\
\text { score }\end{array}$ & $\begin{array}{l}\text { Conserved } \\
\text { branch } \\
\text { length }\end{array}$ & Рст \\
\hline $\begin{array}{l}\text { Position 1030-1036 of HOXA10 3' UTR } \\
\text { hsa-miR-144-3p }\end{array}$ & $\begin{array}{c}5^{\prime} \ldots \text { GUUUGGAUUUCCUUUAUACUGUG } \ldots \\
\text { 3' } \quad \text { UCAUGUAGUAGAUAUGACAU }\end{array}$ & 7mer-m8 & -0.21 & 94 & -0.21 & 4.790 & 0.92 \\
\hline
\end{tabular}

D

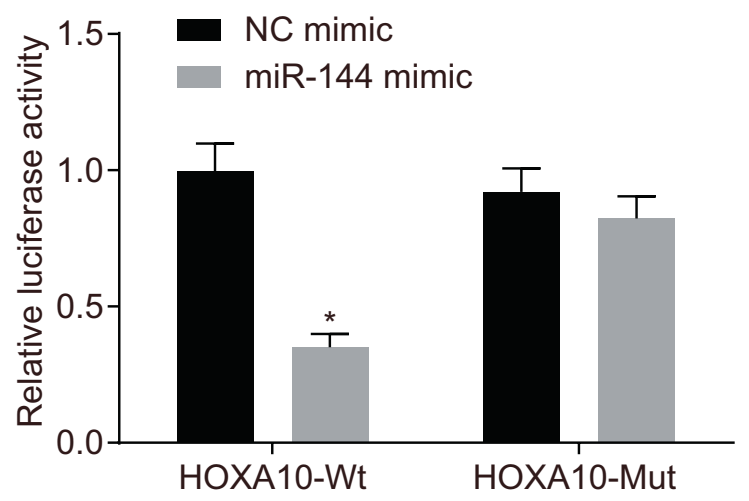

Figure 1 LINC00466 binds to miR-144; HOXA10 is a target gene of miR-144. A: The binding sites of miR-144 and LINC00466. B: The luciferase activity of LINC00466 wt/mut in cells transfected with the miR-144 mimic/negative control (NC) mimic. C: The binding sites of miR-144 and HOXA10. D: The luciferase activity of HOXA10 wt/mut in cells transfected with miR-144 mimic/NC mimic. The measurement data were analyzed by nonpaired $t$-test. The experiment was repeated three times. Data are expressed as means \pm SD (B and $\mathbf{D}) .{ }^{*} P<0.05$ versus cells treated with $\mathrm{NC}$ mimic. $\mathrm{P}_{\mathrm{CT}}$, percentage; UTR, untranslated region. 

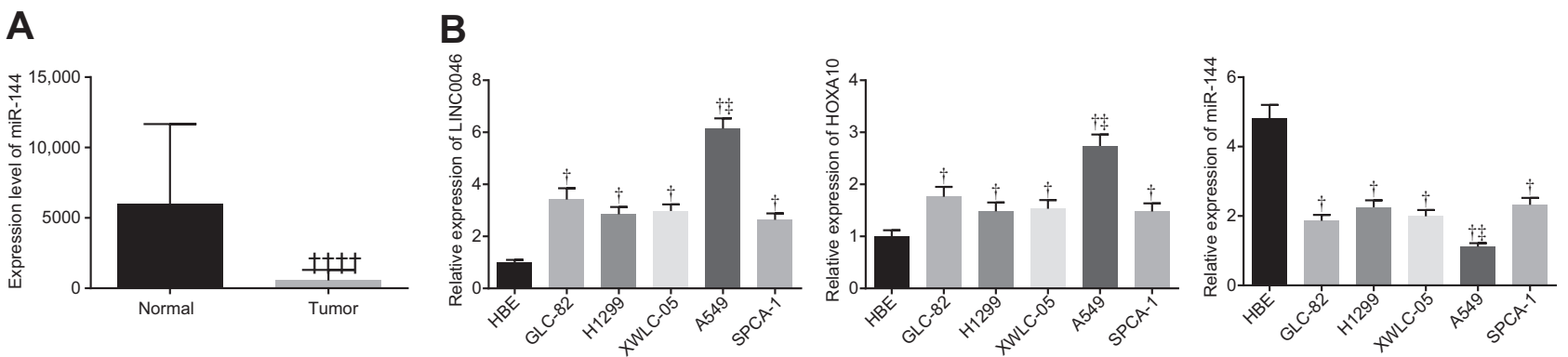

Figure 2 A549 and XWLC-05 cells are selected for later use. A: miR-144 expression in lung adenocarcinoma tissues and normal lung tissues analyzed from The Cancer Genome Atlas database. B: The expression of LINC00466, HOXA10, and miR-144 in lung adenocarcinoma cell lines (GLC-82, H1299, XWLC-05, A549, and SPCA-1) and normal lung cell line (HBE), detected by quantitative RT-PCR. The measurement data were analyzed by one-way analysis of variance. The

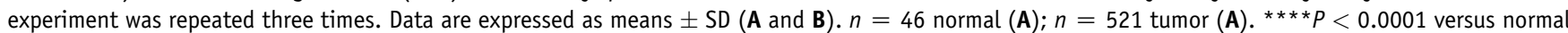
lung tissues; ${ }^{\dagger} P<0.05$ versus HBE cell line; ${ }^{\ddagger} P<0.05$ versus GLC-82, H1299, XWLC-05, and SPCA-1 cell lines.

China). With the culture medium renewed every 24 hours, the cells were grown in monolayer. When cells reached $80 \%$ to $90 \%$ confluence, the process of cell passage was performed. The cell line exhibiting lowest miR-144 expression was screened out with the use of quantitative RT-PCR.

\section{Plasmid Construction and Cell Treatment}

In accordance with the sequence of LINC00466 and miR-144 from the National Center for Biotechnology Information, the plasmids of blank vector, LINC00466, LINC00466 negative control, siRNA (si)-LINC00466 (the plasmid connected with a segment of silencing LINC00466 sequence), negative control blank (the blank plasmid), siRNA negative control (the plasmid connected with a segment of disorder sequence), miR-144 mimic, and si-HOXA10 (the plasmid connected with a segment of silencing HOXA10 sequence) were provided by Shanghai Sangon Biotech Company (Shanghai, China). These plasmids were then respectively delivered into the A549 cells using Lipofectamine 2000 (11668-019; Invitrogen, Carlsbad, CA).

\section{Extraction and Quantitative Analysis of RNA}

From A549 and XWLC-05 cells, the total RNA was isolated with an miRNeasy Mini Kit (217004; Qiagen, Hilden, Germany). Then, with the use of the Primescript RT Reagent Kit (RRO36A; Takara Biotechnology Co Ltd, Dalian, China), the extracted RNAs were reverse transcribed into cDNA. Real-time PCR was conducted using an SYBR Premix Ex Taq II reagent kit (RR820A; Takara Biotechnology Co Ltd) on an ABI7500 real-time quantitative PCR system (7500; ABI Company, Oyster Bay, NY). With glyceraldehyde-3-phosphate dehydrogenase regarded as an internal reference, relative quantification was used to calculate the fold changes. The primers provided by Takara Biotechnology Co Ltd are listed in Table 1.

\section{Western Blot Analysis}

Cells during the logarithmic phase were lysed using radioimmunoprecipitation assay lysis buffer that contained protease inhibitors (Roche, Mannheim, Germany). Consequently, after 10\% SDS-PAGE separation, the cell lysates were transferred onto a polyvinylidene difluoride membrane. This was then incubated with 5\% skim milk for blocking purpose. After that, diluted primary antibodies (Abcam Inc., Cambridge, MA) against human HOXA10 (dilution 1:1000; ab191470), B-cell chronic lymphocytic leukemia/lymphoma 2 (Bcl-2)-associated X protein (dilution 1:2000; ab32503), and Bcl-2 (dilution 1:1000; ab32124) were used to incubate, followed by addition of horseradish peroxidase-conjugated mouse IgG secondary $\mathrm{t}$ antibody (dilution 1:2000; ab97051; Shanghai Yanhui Biotechnology Co., Ltd., Shanghai, China). After this part of the procedure, the membranes were treated with enhanced chemiluminescence reagent (ECL808-25; Biomiga, San Diego, CA), which developed by the X-ray film (Shanghai Westang Bio-Tech Co., Ltd., Shanghai, China), with glyceraldehyde-3-phosphate dehydrogenase set as the internal control.

\section{Immunofluorescence}

Cells cultured on a coverslip were fixed with $4 \%$ paraformaldehyde, blocked with 2\% FBS for 20 minutes, and incubated with $2.5 \mathrm{~mL}$ phycoerythrin-conjugated CD133 antibody at a temperature of $4^{\circ} \mathrm{C}$ for approximately 30 minutes. The coverslip was sealed using glycerol and then examined under a fluorescence microscope.

\section{Flow Cytometry}

After the processes of centrifugation and fixation, $100 \mu \mathrm{L}$ of the cell suspension was stained with RNAase-contained propidium iodide $(50 \mu \mathrm{g})$ alone for 30 minutes for the cell cycle measurement or with both of annexin $\mathrm{V}$-fluorescein isothiocyanate $(10 \mu \mathrm{L})$ and propidium iodide $(5 \mu \mathrm{L})$ for 15 
A

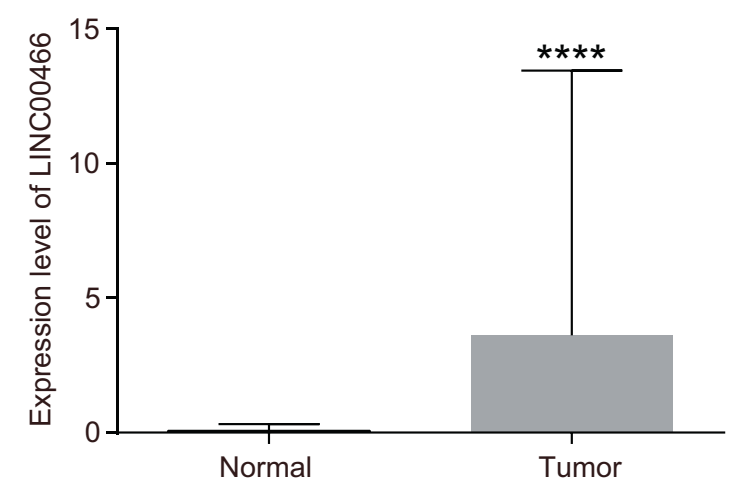

C

B

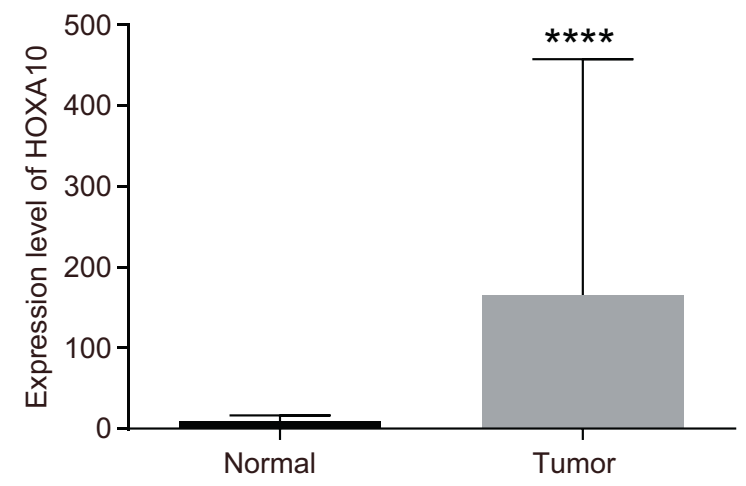

LINC00466

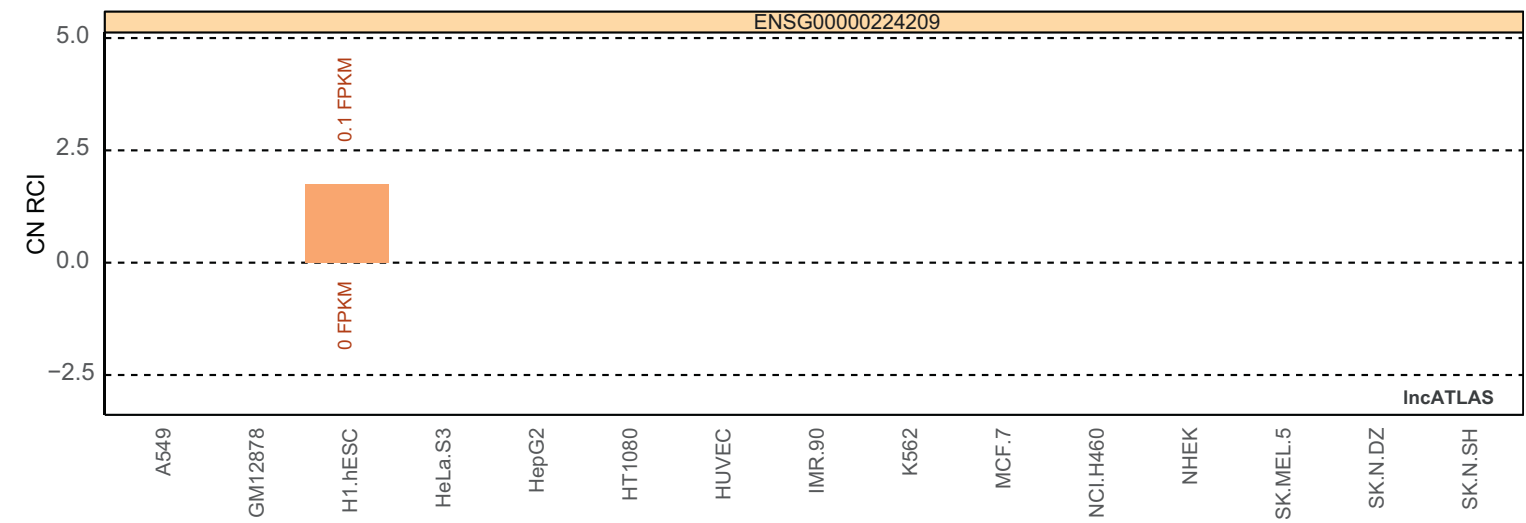

Cell lines $\quad \square-1.5=-1.3=-1.1$

Nuclear expression $[\log 10(\mathrm{FPKM})]=-1.4 \pm-1.2=-1.0$

D
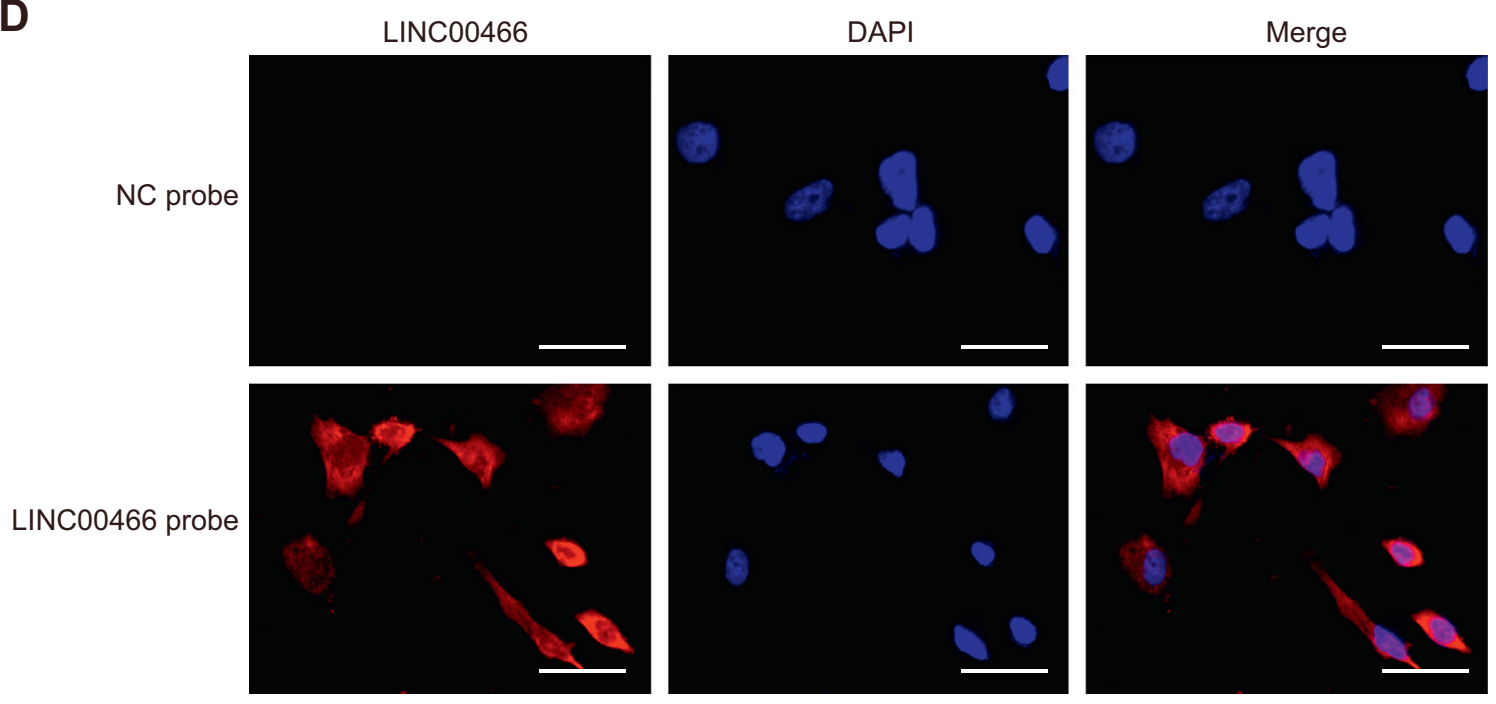

Figure 3 LINCO0466 and HOXA10 are highly expressed in lung adenocarcinoma. A: LINCO0466 expression in lung adenocarcinoma and normal lung tissues analyzed from The Cancer Genome Atlas (TCGA) database. B: HOXA10 expression in lung adenocarcinoma and normal lung tissues analyzed from TCGA database. C: LINC00466 was predicted to be mainly located in the cytoplasm through website prediction (http://lncatlas.crg.eu, last accessed May 28, 2019). D: Subcellular localization of LINC00466 in A549 cells detected by fluorescence in situ hybridization assay. $n=59$ normal (A and B); $n=535$ tumor (A and $\mathbf{B}) .{ }^{* * *} P<0.0001$ versus normal lung tissues. Scale bars $=25 \mu \mathrm{m}$ (D). Original magnification, $\times 400$ (D). CN RCI, the ratio of cytoplasmic to nuclear expression of IncRNA in A549 cells; FPKM, fragments per kilobase of exon model per million mapped fragments; HUVEC, human umbilical vein endothelial cell; NC, negative control. 

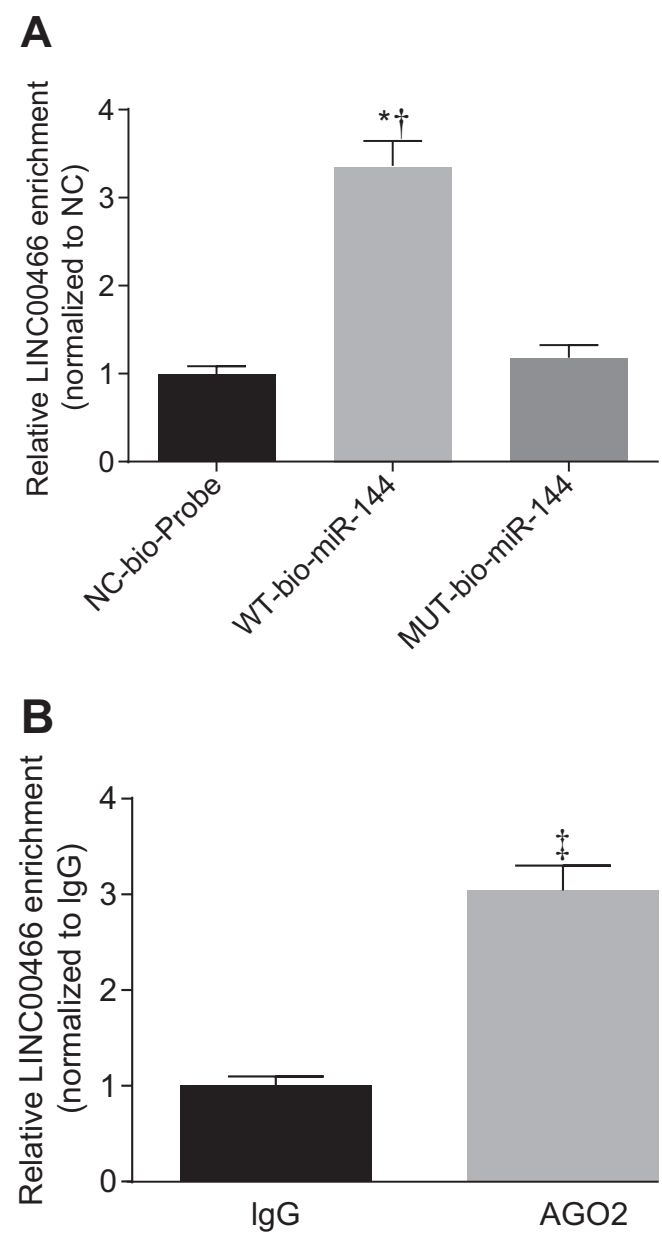

Figure 4 LINCO0466 directly binds to miR-144. A: LINC00466 enrichment detected by RNA pull-down assay. The negative control (NC)-bio-Probe group: A549 cells transfected with NC-bio-Probe; the wtbio-miR-144 group: A549 cells transfected with $50 \mathrm{nmol} / \mathrm{L}$ biotinylated wt-bio-miR-144; the mut-bio-miR-144 group: A549 cells transfected with $50 \mathrm{nmol} / \mathrm{L}$ biotinylated mut-bio-miR-144. The above data were analyzed by one-way analysis of variance. B: miR-144 enrichment detected by RNAbinding protein immunoprecipitation. The measurement data were analyzed by nonpaired independent-sample $t$-test. The experiment was repeated three times. Data are expressed as means \pm SD ( $\mathbf{A}$ and $\mathbf{B})$. ${ }^{*} P<0.05$ versus cells treated with NC-bio-Probe; ${ }^{\dagger} P<0.05$ versus cells treated with mut-bio-miR-144; ${ }^{\ddagger} P<0.05$ versus cells treated with IgG. AG02, Argonaute 2.

minutes in a dim-lit room for the cell apoptosis measurement. The cell cycle and cell apoptosis were studied using a flow cytometer (BD Biosciences, Franklin Lakes, NJ).

\section{Fluorescence in Situ Hybridization Assay}

The fluorescence in situ hybridization assay was conducted by using the Ribo lncRNA fluorescence in situ hybridization Probe Mix (red; RiboBio Co, Ltd, Guangzhou, China). Briefly, the cells in the 24 -well plates $\left(6 \times 10^{4}\right.$ cells/well $)$ were treated with $250 \mu \mathrm{L}$ prehybridization solution at a relatively high temperature of $42^{\circ} \mathrm{C}$ for 1 hour. After this process, $250 \mu \mathrm{L}$ hybridization solution containing $300 \mathrm{ng} /$
$\mathrm{mL}$ probe was used for cell incubation. The next day, the cell staining was performed with diluted DAPI staining solution for approximately 5 minutes. After sealing with an antifluorescence quencher, the results were observed with the use of the fluorescence microscope (Olympus, Tokyo, Japan).

\section{Bioinformatics Website and Dual-Luciferase Reporter Gene Assay}

After the prediction of binding sites of LINCO0466 and miR144 as well as miR-144 and HOXAl online (Thomas Jefferson University, https://cm.jefferson.edu/rna22/Interactive, last accessed May 28, 2019), a dual-luciferase reporter gene assay was further used for verification. The pmirGLO DualLuciferase miRNA Target Expression Vector (Promega, Madison, WI) was used to construct pmirGLO-LINC00466
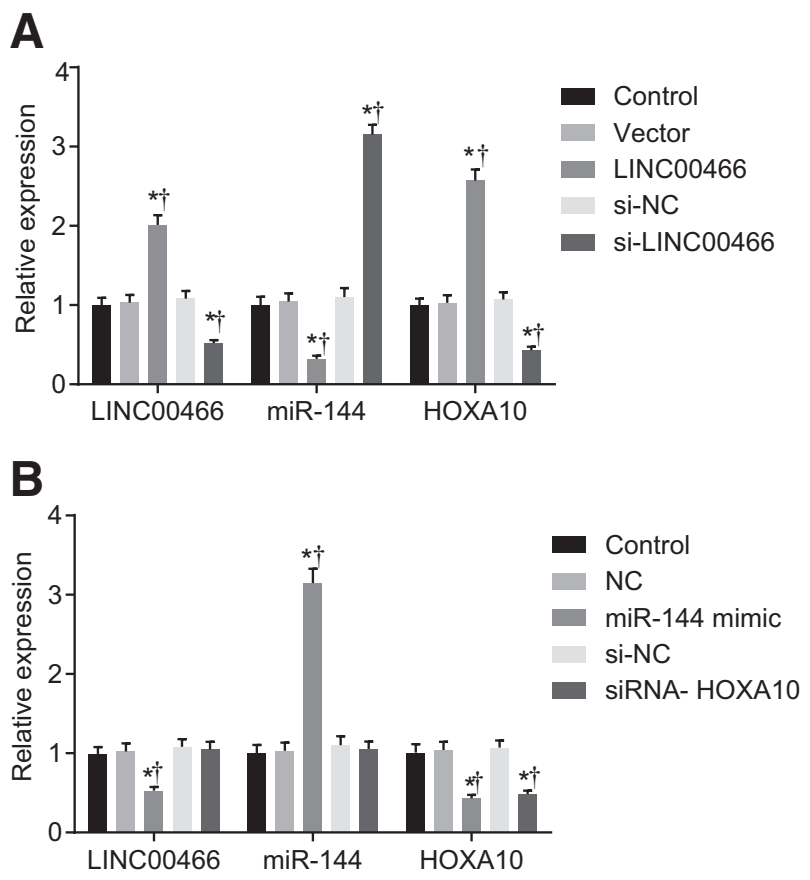

Figure 5 0verexpressing LINC00466 inhibits miR-144 expression and promotes HOXA10 expression. The control group, A549 cells without transfection; the blank vector group, A549 cells transfected with blank plasmid; the LINC00466 group, A549 cells transfected with LINC00466 plasmid; the siRNA negative control (si-NC) group, A549 cells transfected with si-NC plasmid; the si-LINC00466 group, A549 cells transfected with si-LINC00466; the NC group, A549 cells transfected with NC plasmid; the miR-144 mimic group, A549 cells transfected with miR-144 mimic; the si-HOXA10 group, A549 cells transfected with si-HOXA10. A: Expression of LINC00466, miR-144, and HOXA10 in A549 cells overexpressing or silencing LINC00466, detected by quantitative RT-PCR (RT-qPCR). B: Expression of LINC00466, miR-144, and HOXA10 in A549 cells transfected with miR-144 mimic, detected by RT-qPCR. The measurement data were analyzed by oneway analysis of variance. The experiment was repeated three times. Data are expressed as means \pm SD (A and $\mathbf{B})$. ${ }^{*} P<0.05$ versus $A 549$ cells without transfection; ${ }^{\dagger} P<0.05$ versus $A 549$ cells transfected with blank vector, si-NC, or NC plasmids. 
A
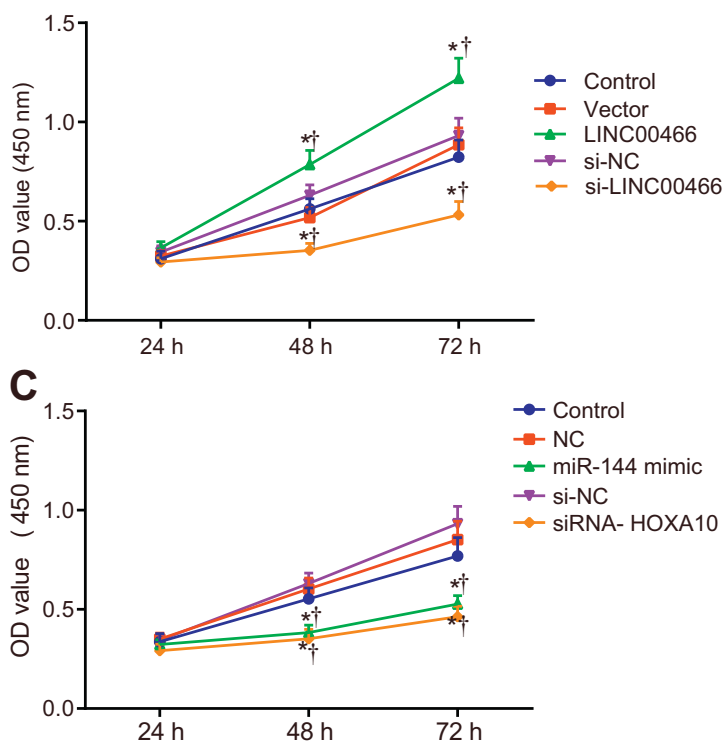

B
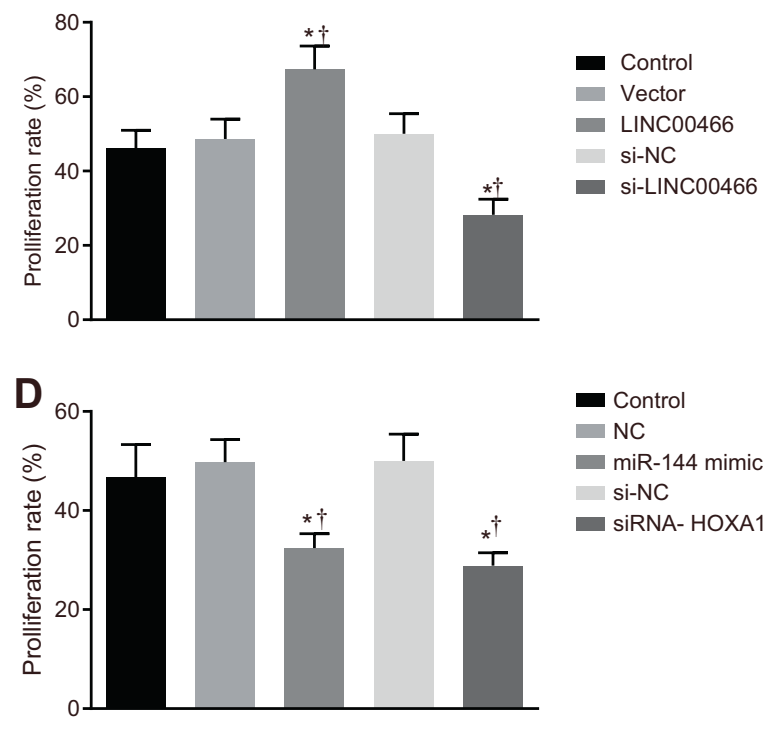

- Control

NC

miR-144 mimic

si-NC

siRNA- HOXA10

Figure 6 Cell proliferation is inhibited by miR-144 and promoted by LINC00466. A: Proliferation of A549 cells interferes with LINC00466 detected by cell counting kit-8 (CCK-8) assay. B: Quantification of results from A. C: Proliferation of A549 cells interferes with miR-144 or HOXA10 detected by CCK-8 assay. D: Quantification of results from C. A and C: Data at different time points were analyzed by repeated analysis of variance. B and D: Data at different time points were analyzed by one-way analysis of variance. The experiment was repeated three times. Data are expressed as means \pm SD (B and $\mathbf{D})$. ${ }^{\star} P<0.05$ versus A549 cells without transfection; ${ }^{\dagger} P<0.05$ versus $A 549$ cells transfected with blank vector, siRNA negative control (si-NC), or NC plasmids.

wild-type (wt) and mutant-type (mut) vectors. The sequences were designed and synthesized on the basis of the potential binding sequence on the $3^{\prime}$-untranslated region of HOXA10 and miR-144. The HOXA10-wt sequence was $5^{\prime}$-UGGAUUUCCUUUAUACUGUG-3'; the HOXA10-mut sequence was $5^{\prime}$-UGGUUUAGCAUA $\bar{U}$ UAUGACAG-3' (the underlined parts are not the binding sites of HOXA10 to miR144, so the base remains unchanged); the LINC00466-wt sequence was 5'-CCCCCAGTAAAGCTACAAAGGGA TTACCAGCGTT- $3^{\prime}$; and the LINC00466-mut sequence was 5'-GGGGGTGTAAAGGTTGTATCGCTTTTGCAGGGTT$3^{\prime}$. The wt or mut luciferase plasmids were then delivered into the cells. It was not a concern whether they contained miR-144. Afterward, the luciferase activity was evaluated with the use of Genecopoeia's Dual Luciferase Assay Kit (RG027; Beyotime Institute of Biotechnology, Beijing, China) by a Promega Glomax 20/20 luminometer fluorescence detector (E5311; Shaanxi Zhongmei Biotechnology Co., Ltd., Xian, China).

\section{RNA Pull-Down Assay}

To continue, the $50 \mathrm{nmol} / \mathrm{L}$ biotinylated wt-bio-miR-144 and mut-bio-miR-144 were delivered into the A549 cells, which were then lysed. After being precoated with RNasefree bovine serum albumin and yeast tRNA at a temperature of $4^{\circ} \mathrm{C}$ for 3 hours, the M-280 streptavidin magnetic beads (S3762; Chemical Company, St. Louis, MO) were used for cell incubation. After this, after washing by low-salt buffer (three times) and high-salt buffer (once), the bound RNA was purified to discover the LINC00466 enrichment through RNA isolation and quantification.

\section{RNA-Binding Protein Immunoprecipitation Assay}

The binding ability of LINC00466 to Argonaute 2 (AGO2) protein was revealed with the use of the RNA-binding protein immunoprecipitation kit (Millipore, Bedford, MA). A part of the cell extract served as the input, and the remaining part was incubated at $4^{\circ} \mathrm{C}$ overnight with magnetic bead-antibody complex. After the collection of magnetic bead-protein complexes, the RNAs of samples and inputs were extracted for quantitative RT-PCR. The antibodies were AGO2 (diluted 1:50; ab32381; Abcam, Cambridge, UK) and IgG (dilution 1:100; ab109489; Abcam) as a negative control.

\section{Colony Formation Assay}

As a result, 800 cells were inoculated to each $75-\mathrm{mm}$ dish (single cells in suspension $>95 \%$ ). Then, the cells were further incubated for another 9 days, fixed with formaldehyde for 20 minutes, and finally stained with $10 \%$ Giemsa for 20 minutes. Subsequently, the numerical amount of cell colonies with $>20$ cells in each dish was through the use of the anatomic lens. After this, the colony-forming efficiency was calculated.

\section{Sphere Formation Assay}

Moreover, the A549 and XWLC-05 cells were cultured in high-glucose Dulbecco's modified Eagle's medium with $10 \% \mathrm{FBS}$ in $5 \% \mathrm{CO}_{2}$ at $37^{\circ} \mathrm{C}$. Next, the cells were inoculated in a 6-well ultralow cell adhesion plate (the 
A

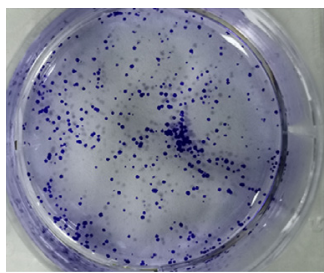

B

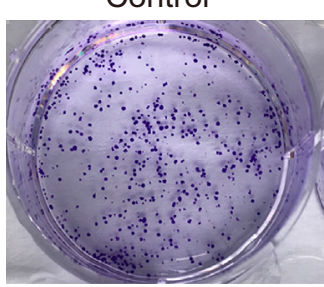

C

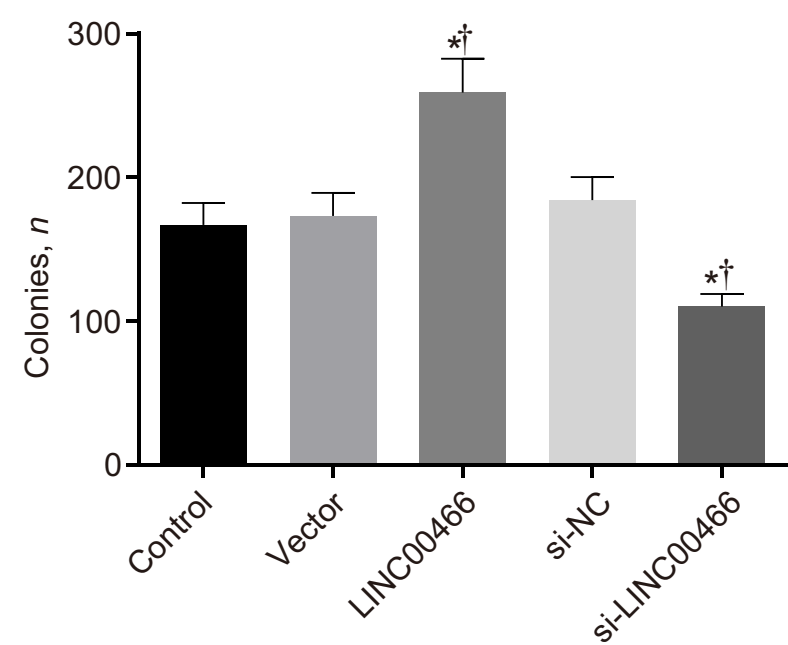

LINC00466

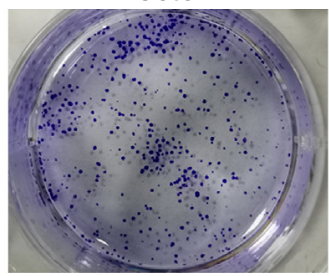

NC

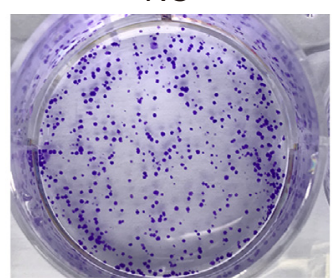

miR-144 mimic

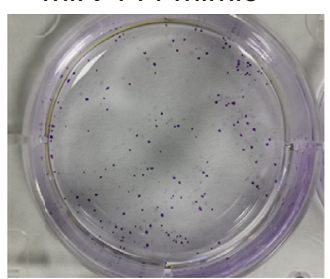

si-NC

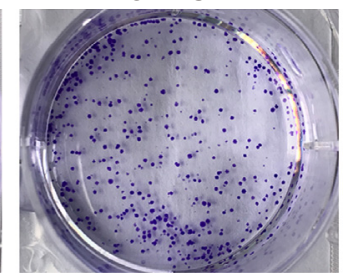

si-NC

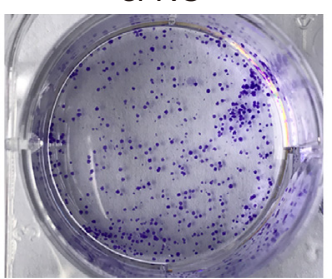

si-LINC00466

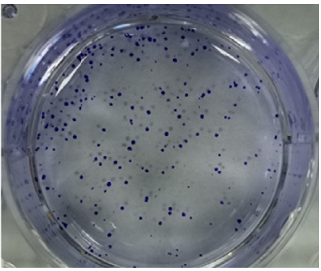

SiRNA-HOXA10

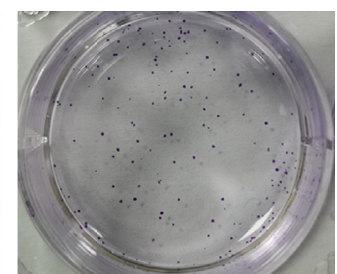

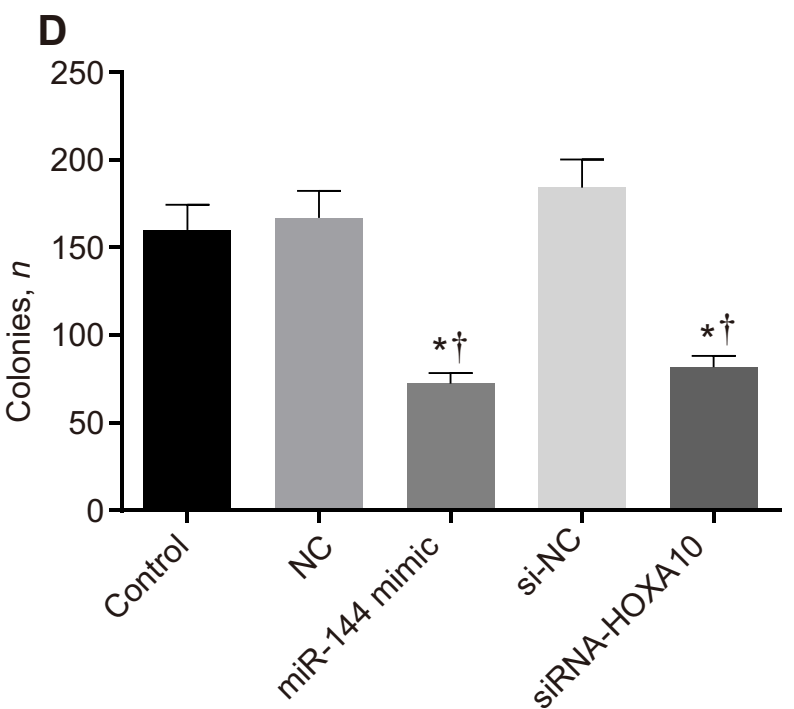

Figure 7 Colony formation is inhibited by silencing LINC00466 or HOXA10 or by overexpressing miR-144. Colony formation of A549 cells interfered with LINC00466 (A and C) and miR-144 (B and D) detected by colony formation assay. The measurement data were analyzed by one-way analysis of variance. The experiment was repeated three times. Data are expressed as means \pm SD (C and $\mathbf{D})$. ${ }^{*} P<0.05$ versus A549 cells without transfection; ${ }^{\dagger} P<0.05$ versus A549 cells transfected with blank vector, siRNA negative control (si-NC), or NC plasmids.

density was $<1000$ cells/well) in $5 \% \mathrm{CO}_{2}$ at $37^{\circ} \mathrm{C}$. After a period of 6 days, the tumor cell sphere was measured to be approximately $50 \mu \mathrm{m}$ in diameter. The cell sphere was detached with $0.25 \%$ trypsin and $0.02 \%$ EDTA at $37^{\circ} \mathrm{C}$ for 2 minutes and triturated to single cells. Afterward, the cells were counted and inoculated once again in a 6-well ultralow plate (BD, Franklin Lakes, NJ).

\section{Cell Viability Detection}

The cells were cultured with Dulbecco's modified Eagle's medium that contained $10 \%$ FBS in 96-well plates $\left(1 \times 10^{4}\right.$ cells $/ \mathrm{mL}$ ) with $5 \% \mathrm{CO}_{2}$ at a temperature of $37^{\circ} \mathrm{C}$. After a period of 24 to 72 hours, each well of the plate was incubated with $10 \mu \mathrm{L}$ of cell counting kit-8 solution (SigmaAldrich, St. Louis, MO) for approximately 2 hours. The OD at the wavelength of $450 \mathrm{~nm}$ was obtained through a multimode microplate reader (NYW-96M; Peking Nuoya wei Instrument Co., Ltd., Beijing, China).

\section{Scratch Test}

Furthermore, when cell confluence reached around a percentage of $90 \%$, scratches were generated using sterile pipette tips. After that, the cells were cultured with a serumfree medium. The migration distance was measured with the use of the Image-Pro Plus Analysis software version 7.0 (Media Cybernetics, Inc., Rockville, MD).

\section{Transwell Assay}

The upper side of a transwell filter chamber was covered by Matrigel (50 $\mu \mathrm{L} ; 356234 ; \mathrm{BD})$. The 

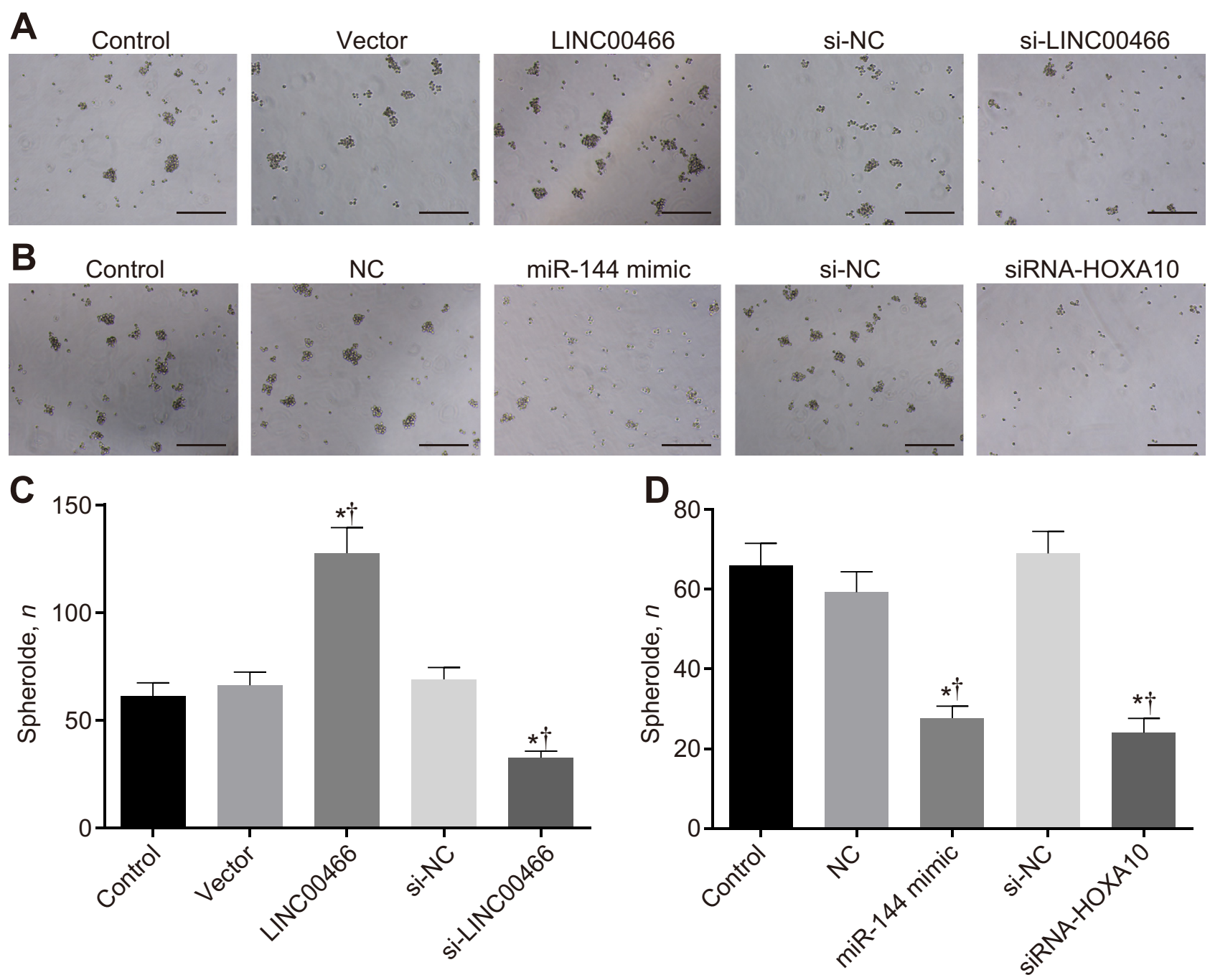

Figure 8 Knocking down LINCO0466 or HOXA10 or up-regulating miR-144 inhibits sphere formation. Sphere formation of A549 cells interferes with LINC00466 (A and C) and miR-144 (B and D) detected by sphere formation assay. The measurement data were analyzed by one-way analysis of variance. The experiment was repeated three times. Data are expressed as means \pm SD (C and $\mathbf{D}) .{ }^{*} P<0.05$ versus A549 cells without transfection; ${ }^{\dagger} P<0.05$ versus $\mathrm{A} 549$ cells transfected with blank vector, siRNA negative control (si-NC), or NC plasmids. Scale bars $=100 \mu \mathrm{m}(\mathbf{A}$ and $\mathbf{B})$. Original magnification, $\times 100(\mathbf{A}$ and $\mathbf{B})$.

transfected cells $\left(1 \times 10^{5}\right.$ cells $\left./ \mathrm{mL}\right)$ were seeded at $37^{\circ} \mathrm{C}$ into the apical chamber of the transwell filter and incubated in a serum-free medium for exactly 24 hours (the basolateral chamber was added with medium containing $10 \%$ FBS). The invasive cells on the lower side of the filter were fixed with 5\% glutaraldehyde, stained with $0.1 \%$ crystal violet, and counted under a microscope. The number of cells passing through matrix gum in each group served as an index to determine their invasive ability.

\section{In Vivo Tumor Formation Assay}

The anesthetized nude mice were subcutaneously inoculated with the A549 cells that were already transfected with LINC00466, si-LINCO0466, miR-144 mimic, or si-HOXA10 plasmids $\left(1 \times 10^{6}\right.$ cells $\left./ 200 \mu \mathrm{L}\right)$ at the back of their right hind leg. Moreover, the mice were observed periodically every 4 days. After this, their tumor volume was calculated by the following equation: (length $\times$ width) ${ }^{2} / 2$.

Specifically, on the 25th day, the mice were euthanized with the tumors collected, with three tumor samples collected in each group.

\section{Statistical Analysis}

All data in this study were processed by SPSS 21.0 (IBM Corp., Armonk, NY). Measurement data were expressed as means $\pm \mathrm{SD}$. A $t$-test was performed to analyze the comparison between two groups. For the normally distributed data with homogeneity of variance, the nonpaired independent-sample $t$-test was implemented. The normality test of data was performed using the Kolmogorov-Smirnov method, and one-way analysis of 
A

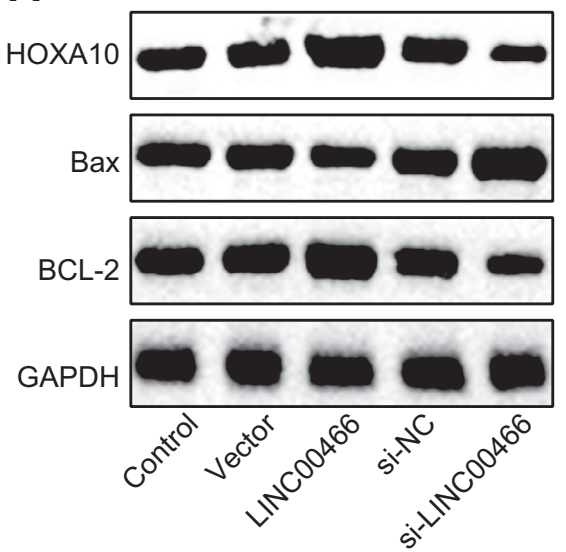

C

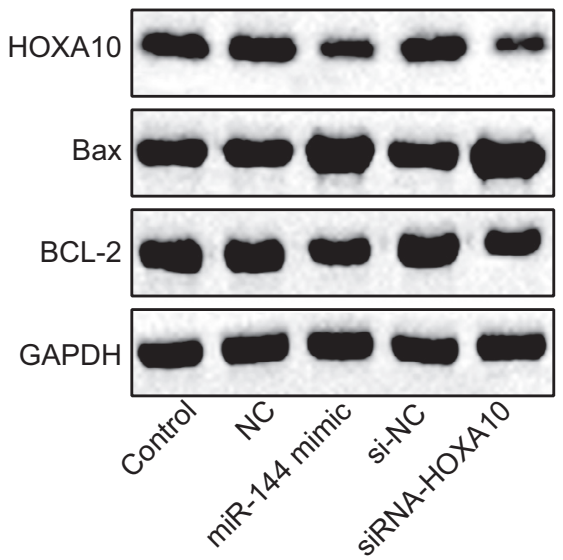

B

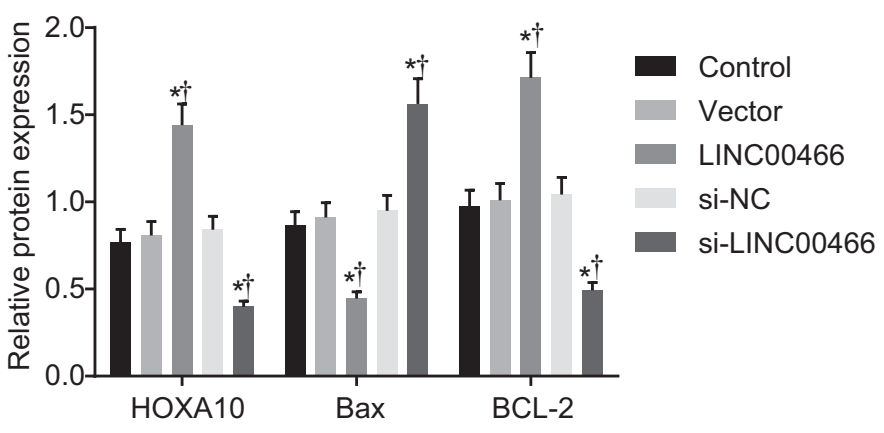

D

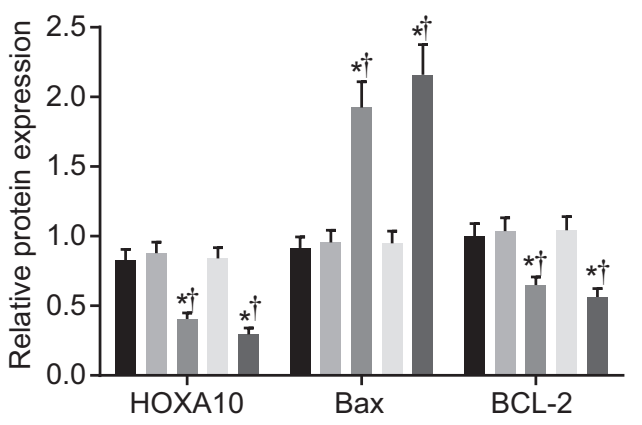

Control

NC

miR-144 mimic

si-NC

siRNA-HOXA10

Figure 9 The expression of HOXA10 and B-cell chronic lymphocytic leukemia/lymphoma 2 (Bcl-2) is decreased, whereas the expression of $\mathrm{Bcl}-2$-associated $\mathrm{X}$ protein (Bax) is increased, by silencing LINCOO466 or overexpressing miR-144. The expression of HOXA10, Bax, and Bcl-2 at protein level in A549 cells interferes with LINC00466 (A and B) and miR-144 (C and D), detected by Western blot analysis. The measurement data were analyzed by one-way analysis of variance. The experiment was repeated three times. Data are expressed as means $\pm \mathrm{SD}$ (B and $\mathbf{D}$ ). ${ }^{*} P<0.05$ versus A549 cells without transfection; ${ }^{\dagger} P<0.05$ versus A549 cells transfected with blank vector, siRNA negative control (si-NC), or NC plasmids. GAPDH, glyceraldehyde-3phosphate dehydrogenase.

variance was used to compare data among multiple groups with Tukey post hoc test when the data were normally distributed. The cell viability at different time points among different groups was compared by using repeatedmeasurement analysis of variance. $P<0.05$ was considered significant.

\section{Results}

\section{LINC00466 Binds to miR-144, which Targets HOXA10}

The cells transfected with $m i R-144$ mimic exhibited lower luciferase activity of LINC00466-wt $(P<0.05)$, whereas they exhibited no difference in luciferase activity of LINC00466-mut $(P>0.05)$ (Figure 1, A and B), suggesting that LINC00466 could exclusively bind to miR-144. Cells transfected with $m i R-144$ mimic depicted decreased luciferase activity of $H O X A 10$-wt $(P<0.05)$, but displayed no difference in the luciferase activity of $H O X A 10$-mut
$(P>0.05)$, suggesting a targeting relationship between HOXA10 and miR-144 (Figure 1, C and D).

\section{The A549 and XWLC-05 Cell Lines Are Chosen}

Initially, the expression data of genes and miRNAs related to lung adenocarcinoma from The Cancer Genome Atlas database were analyzed on the basis of the R software, which showed that $m i R-144$ expression was lower in lung adenocarcinoma relative to that in a normal lung (Figure 2A). Next, the expression of $m i R-144$, LINC00466, and HOXA10 in different lung adenocarcinoma cell lines (GLC-82, H1299, XWLC-05, A549, and SPCA-1) and normal lung cell line (HBE) was measured. $m i R-144$ expression was significantly lower, and expression of LINC00466 and HOXA10 was higher, in the five lung adenocarcinoma cell lines relative to those in normal lung cell line $\mathrm{HBE}(P<0.05)$, with the most significant change involving the expression level of $m i R-144$, 

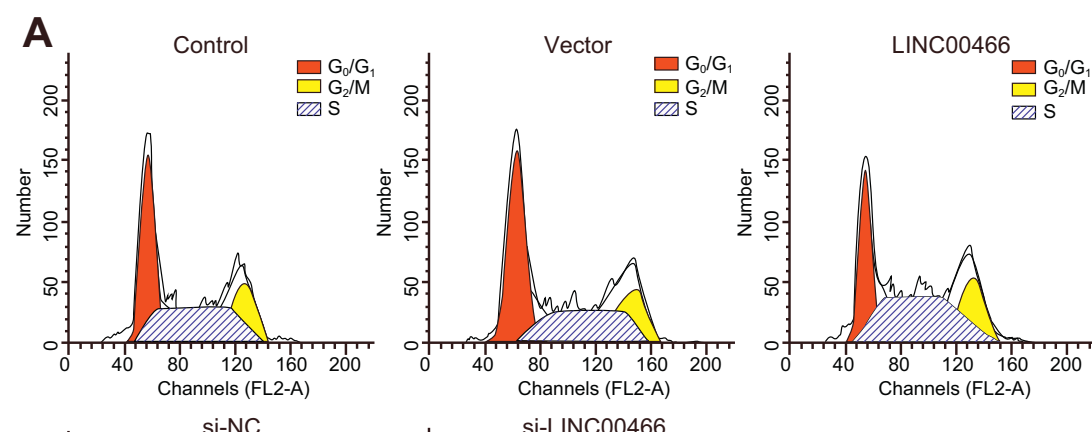

$\mathbf{B}$
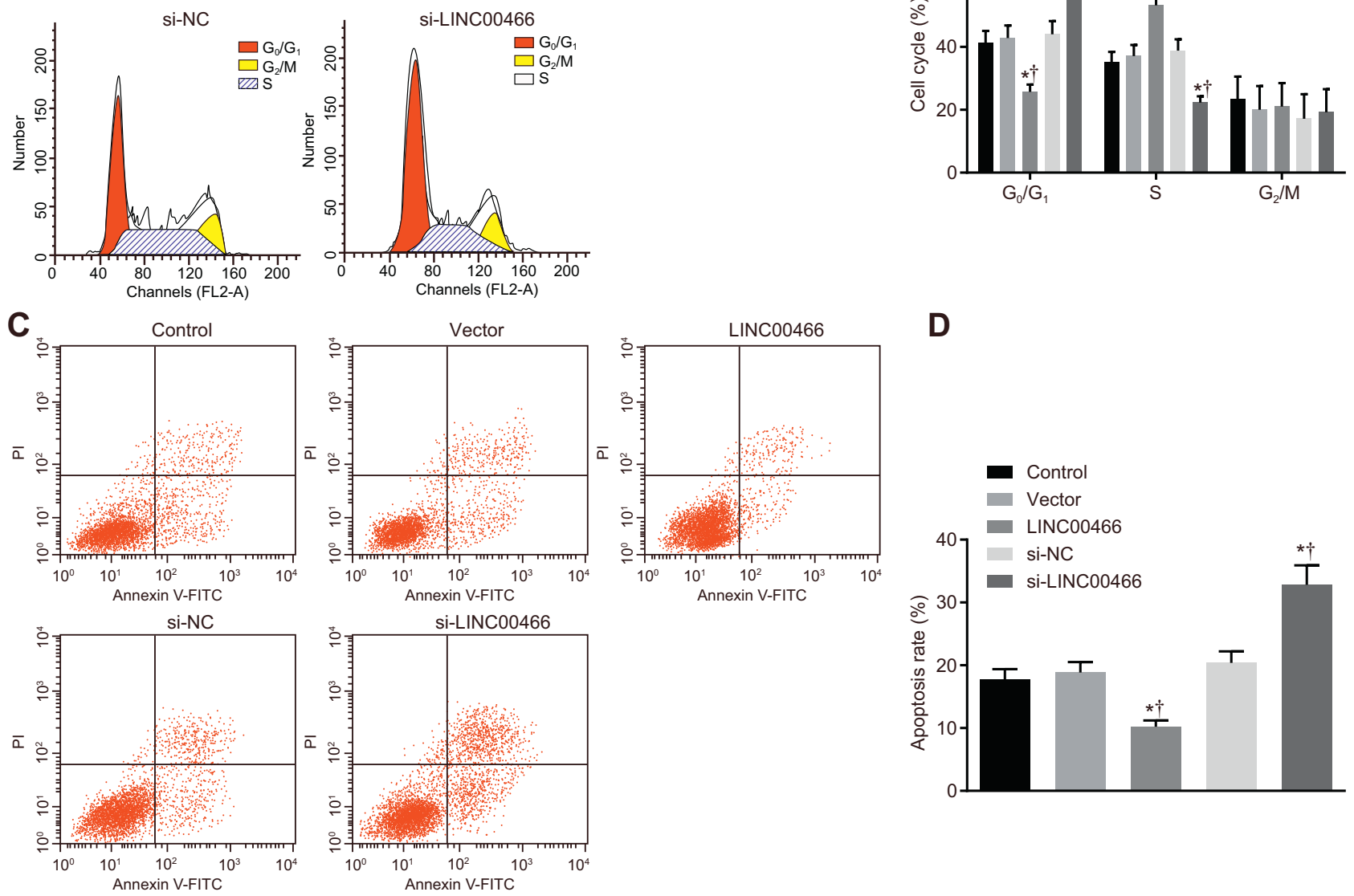

Figure 10 Cells are arrested at the $G_{0} / G_{1}$ phase, and cell apoptosis is induced by silencing LINC00466. Cell cycle analysis (A and B) and cell apoptosis rates (C and D) of A549 cells interferes with LINC00466, detected by flow cytometry. The measurement data were analyzed by one-way analysis of variance. The experiment was repeated three times. Data are expressed as means \pm SD (B and $\mathbf{D}) .{ }^{*} P<0.05$ versus A549 cells without transfection; ${ }^{\dagger} P<0.05$ versus $\mathrm{A} 549$ cells transfected with blank vector or siRNA negative control (si-NC) plasmids. FITC, fluorescein isothiocyanate; PI, propidium iodide.

LINC00466, and HOXA10 found in the A549 and XWLC-05 cell lines (Figure 2B). Therefore, the A549 and XWLC-05 cell lines were used in the following experiment.

\section{LINC00466 Regulates HOXA10 through Competitively Binding to miR-144}

Microarray-based gene expression analysis showed high expression of LINC00466 and HOXA10 in lung adenocarcinoma (Figure 3, A and B). Website prediction is available at IncATLAS (http://lncatlas.crg.eu, last accessed May 28, 2019), and fluorescence in situ hybridization assay further presented that LINCO0466 was mainly located in the cytoplasm (Figure 3, C and D). Furthermore, RNA pull down, together with the RNA-binding protein immunoprecipitation assay, was performed to determine the binding ability of LINCO0466 to miR-144 and LINCO0466 to AGO2, respectively. The results indicated that LINC00466 enrichment was increased in wt-miR-144 when compared with mut$m i R-144(P<0.05)$ (Figure 4A), revealing that miR-144 directly binds to LINC00466. When compared with IgG, the binding of LINC00466 with AGO2 was significantly increased, suggesting that LINC00466 could bind to AGO2 $(P<0.05)$ (Figure 4B) and suggesting that LINC00466 could competitively bind to miR-144 through binding to AGO2. 

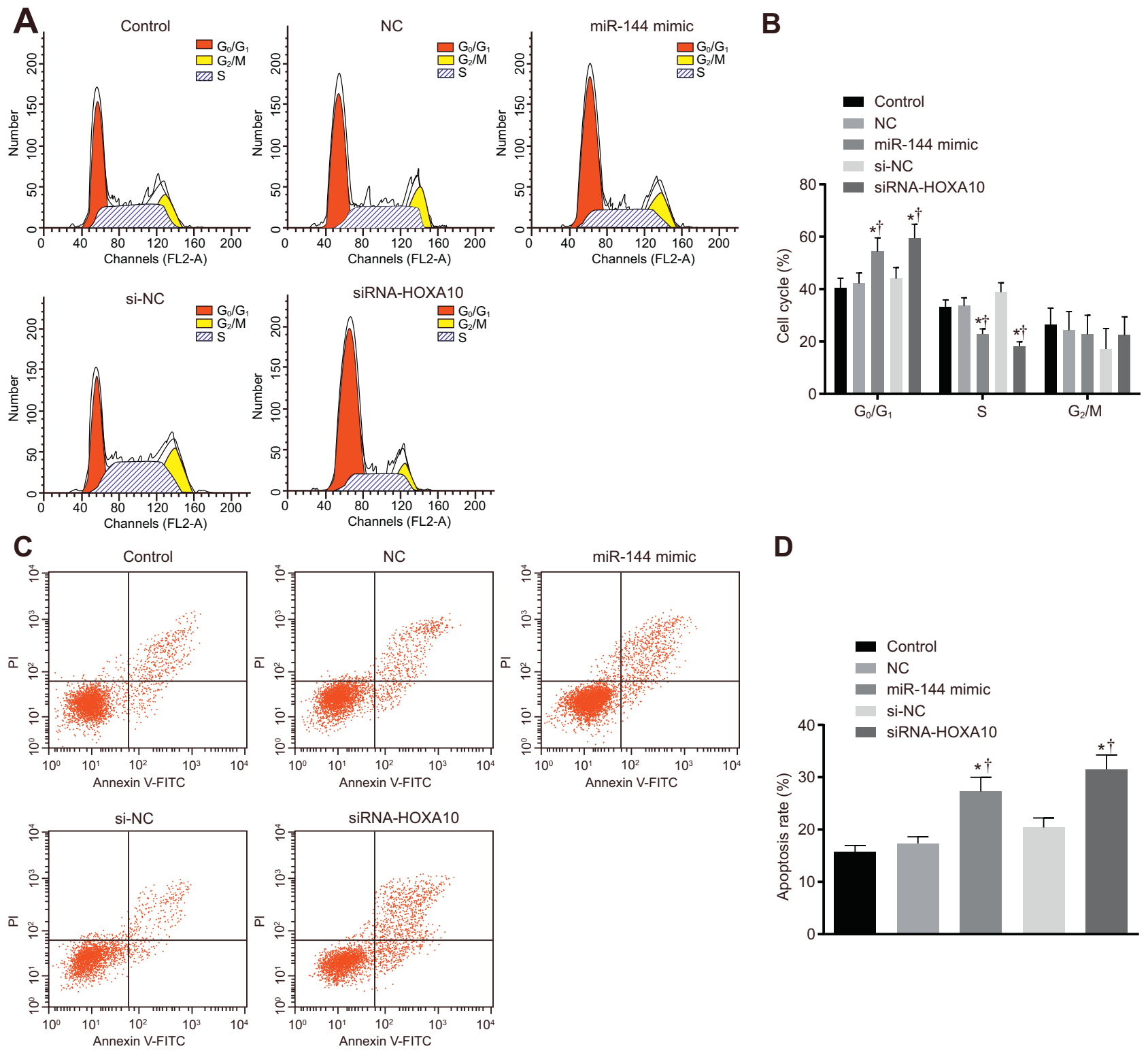

Figure 11 Cells are arrested at the $\mathrm{G}_{0} / \mathrm{G}_{1}$ phase, and cell apoptosis is caused by elevating miR-144. Cell cycle analysis (A and B) and cell apoptosis rates (C and D) of A549 cells interfere with miR-144, detected by flow cytometry. The measurement data were analyzed by one-way analysis of variance. The experiment was repeated three times. Data are expressed as means \pm SD (B and $\mathbf{D}) .{ }^{\star} P<0.05$ versus A549 cells without transfection; ${ }^{\dagger} P<0.05$ versus A549 cells transfected with siRNA negative control (si-NC) or NC plasmids. FITC, fluorescein isothiocyanate; PI, propidium iodide.

Moreover, the targeting relationship among LINC00466, miR-144, and HOXA10 was broadened and confirmed. After overexpressing LINC00466, A549 and XWLC-05 cells revealed down-regulation of $m i R-144$ but upregulation of LINC00466 and HOXA10, whereas those transfected with si-LINC00466 showed the opposite results $(P<0.05)$ (Figure 5A). Moreover, the A549 and XWLC-05 cells after miR-144 mimic treatment showed decreased LINCOO466 and HOXA1O and increased miR$144(P<0.05)$. Furthermore, cells after si-HOXA10 treatment presented down-regulated HOXA10 expression $(P<0.05)$ while having no evident change in the expression level of LINC00466 and miR-144 $(P>0.05)$
(Figure 5B). Thus, overexpressing LINC00466 has the potential to inhibit miR-144 expression and promote HOXA10 expression, while simultaneously overexpressing $m i R-144$ could inhibit the expression of LINCO0466 and HOXA10.

Silencing LINCO0466 and HOXA10 or Overexpressing miR-144 Inhibits Cell Proliferation, Colony Formation, and Sphere Formation in Lung Adenocarcinoma

The functions of LINC00466, HOXA10, and miR-144 in lung adenocarcinoma A549 cells were detected through cell counting kit-8 (Figure 6), colony formation (Figure 7), and 

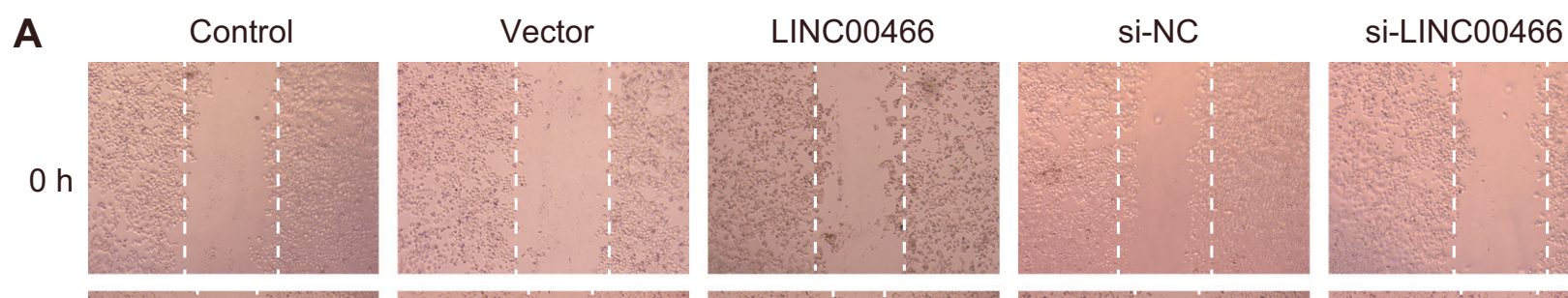

$24 \mathrm{~h}$
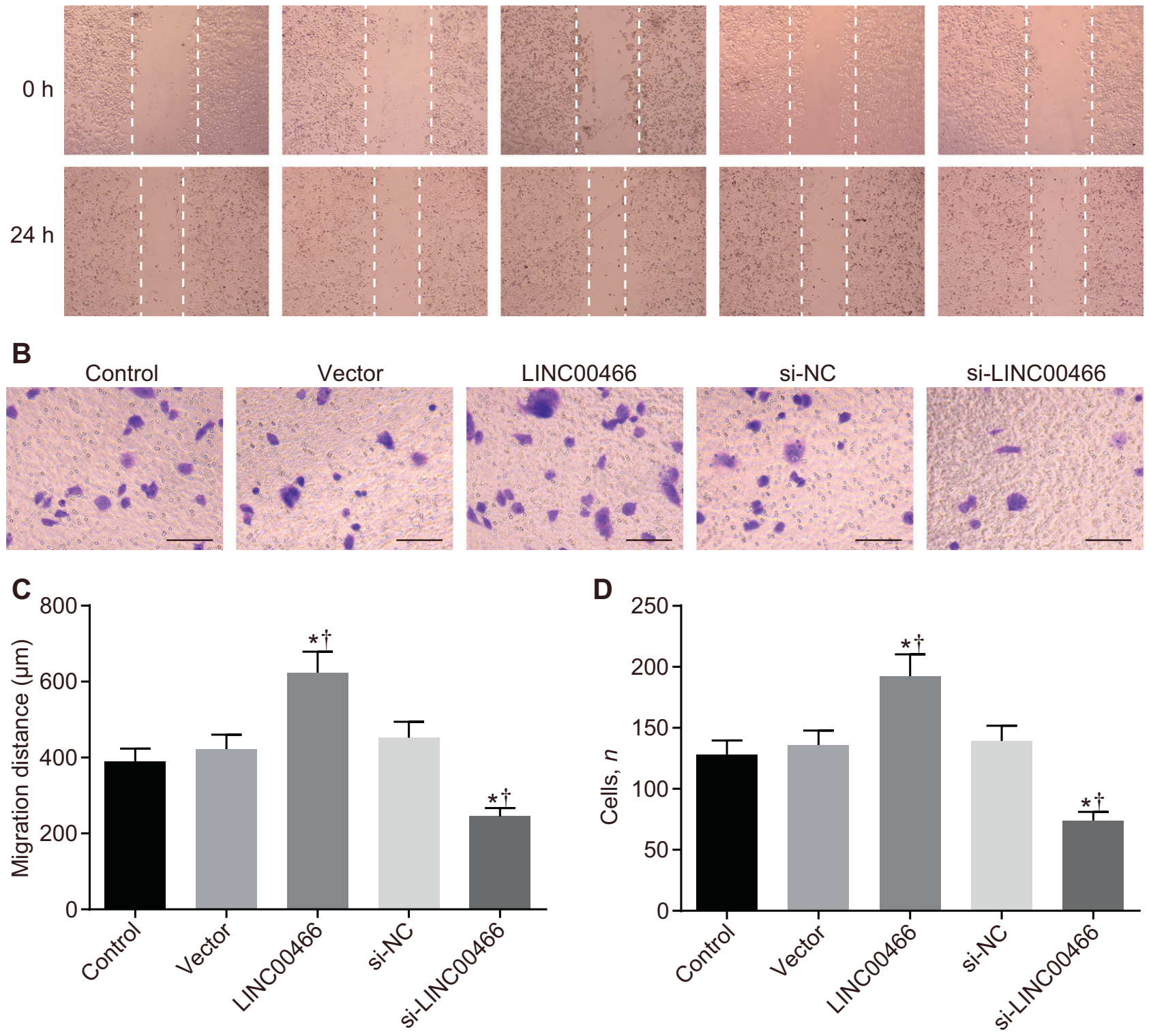

Figure 12 Cell migration and invasion are inhibited by silencing LINC00466. Cell migration (A and C) and cell invasion (B and D) of A549 cells interfered with LINC00466, detected by scratch test (A and C) and transwell assay (B and D). A: Dashed lines denote the edge of areas without cells, and the distance between two dashed white lines is the scratch width. The measurement data were analyzed by one-way analysis of variance. The experiment was repeated three times. Data are expressed as means \pm SD (C and D). ${ }^{*} P<0.05$ versus A549 cells without transfection; ${ }^{\dagger} P<0.05$ versus A549 cells transfected with blank vector or siRNA negative control (si-NC) plasmids. Scale bars $=50 \mu \mathrm{m}(\mathbf{B})$. Original magnification: $\times 40(\mathbf{A}) ; \times 200(\mathbf{B})$.

sphere formation (Figure 8) assays. The results showed that in A549 cells, overexpression of LINC00466 promoted cell proliferation, colony formation, and sphere formation. However, it also silenced LINC00466, which induced the opposite results $(P<0.05)$. Nonetheless, after $m i R-144$ mimic or si-HOXA10 treatment, the A549 cells showed inhibited cell proliferation, colony formation, and sphere formation $(P<0.05)$. Furthermore, the above experiments were repeated in XWLC-05 cells, the results of which were similar to those found in A549 cells (Supplemental Figures S1, S2, and S3). The aforementioned results demonstrated that cell proliferation, colony formation, and sphere formation were inhibited by silencing LINC00466 and HOXA10 or overexpressing miR-144.

Depletion of LINC00466 and HOXA10 or Overexpression of miR-144 Promotes Cell Apoptosis in Lung

\section{Adenocarcinoma}

The functions of LINC00466, HOXA10, and miR-144 in apoptosis of lung adenocarcinoma A549 cells were discovered through Western blot analysis (Figure 9) and flow cytometry (Figures 10 and 11). After overexpressing LINC00466, the expression of $\mathrm{Bcl}-2-$ associated $\mathrm{X}$ protein, 
A
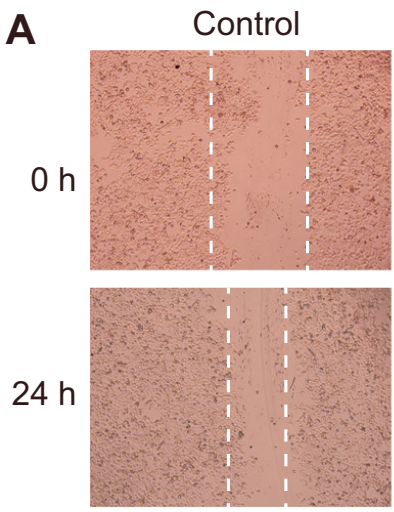

B Control

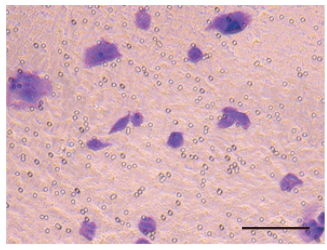

C
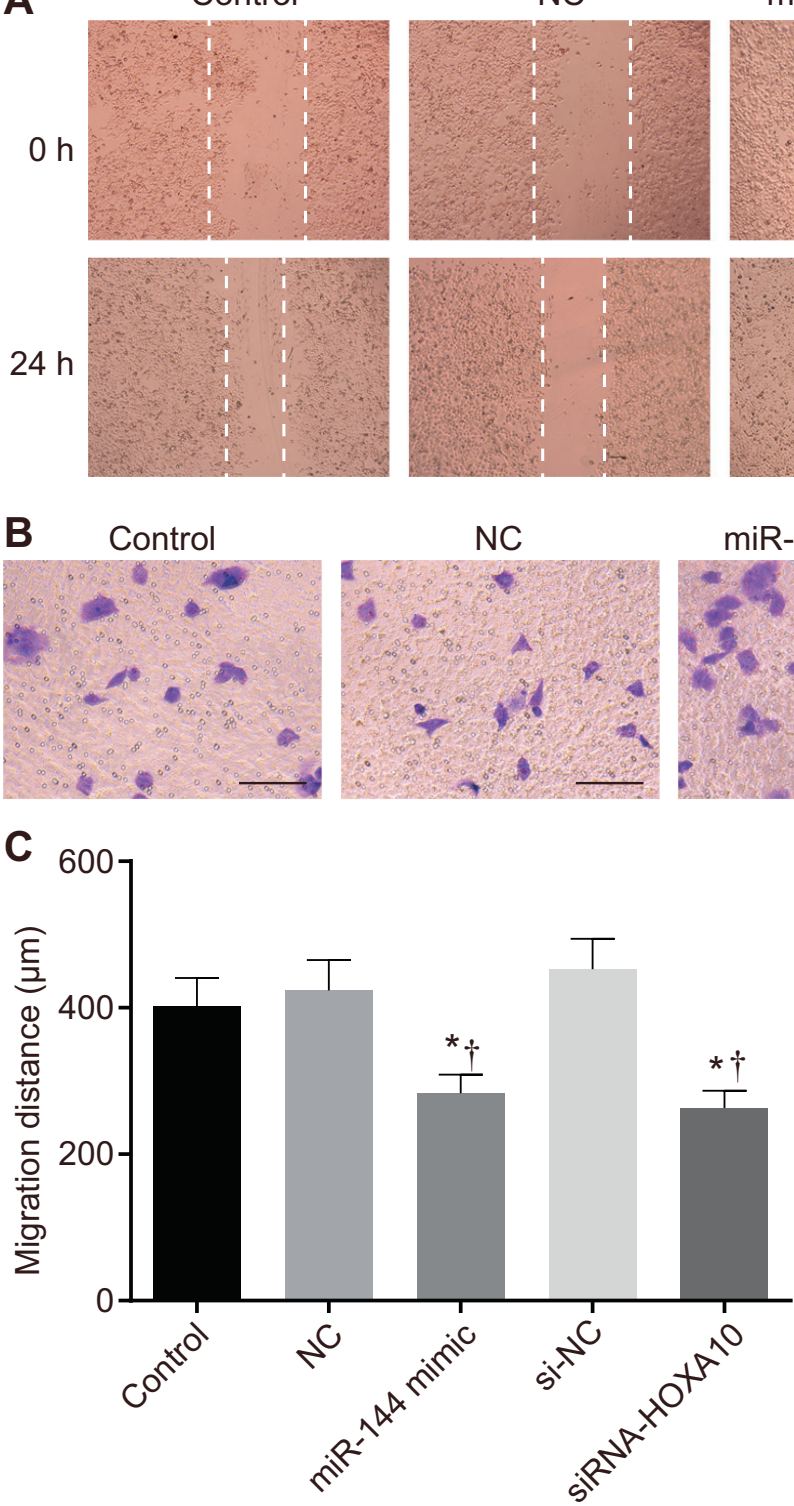

NC

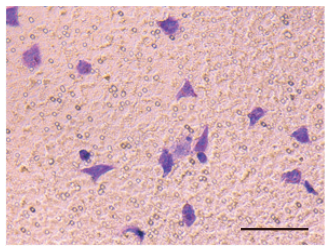

miR-144 mimic
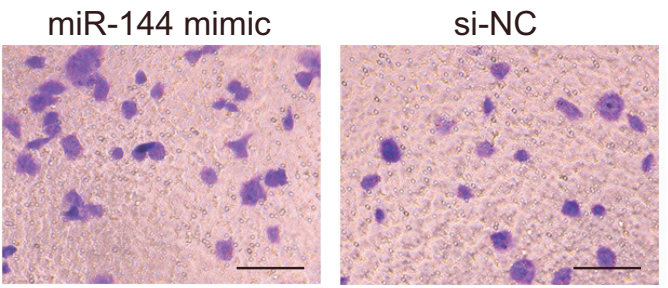

SIRNA-HOXA10

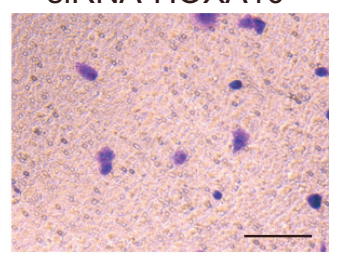

D 200

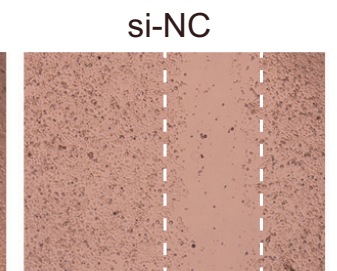

SiRNA-HOXA10
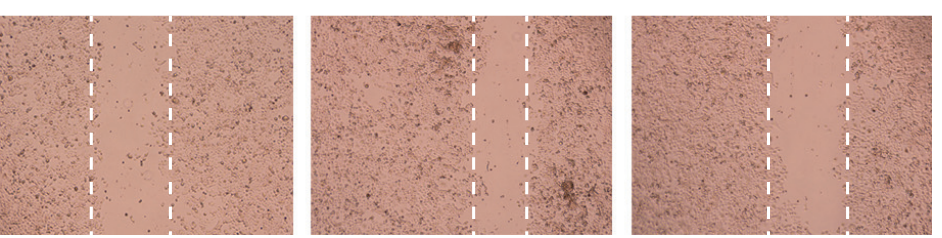
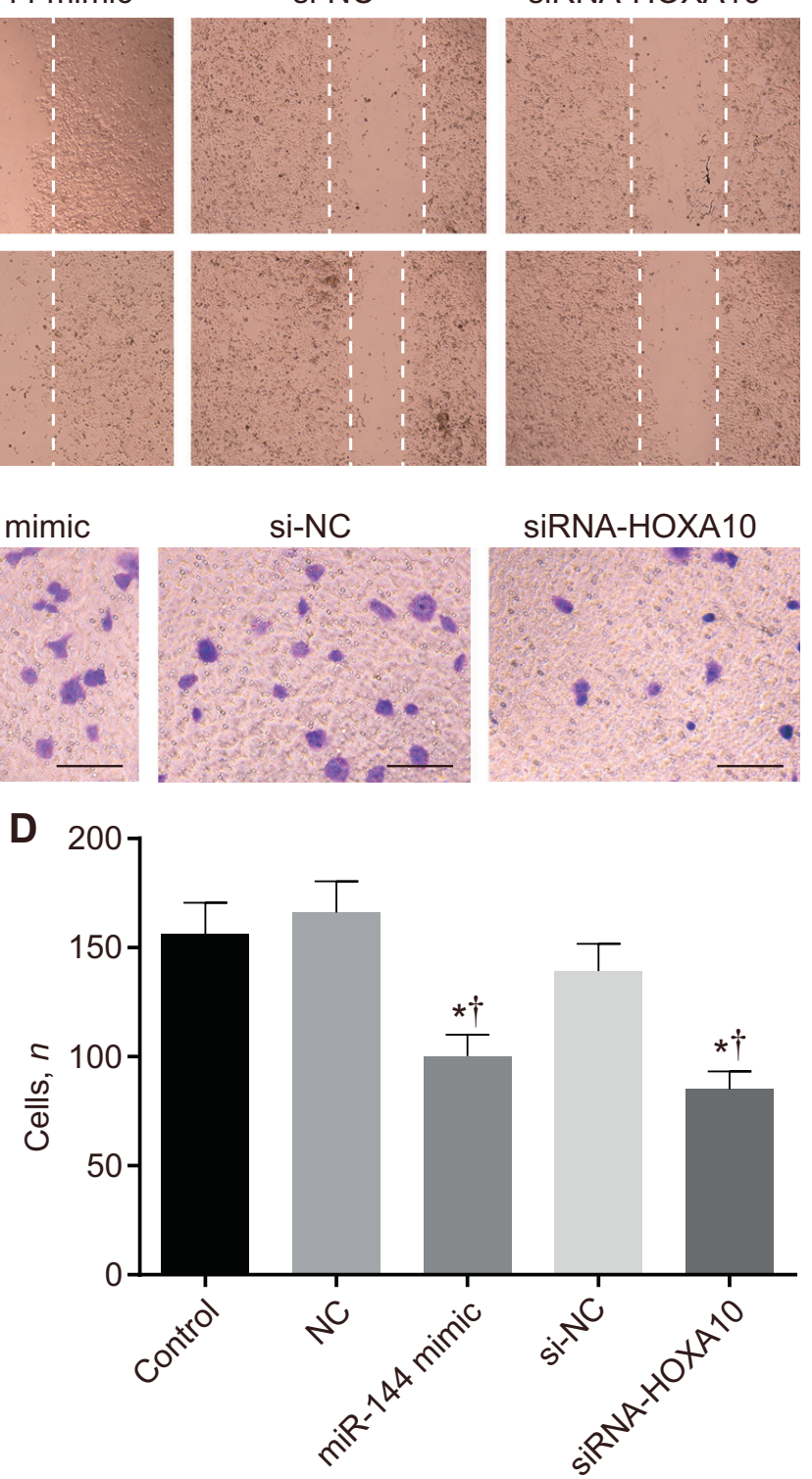

Figure 13 Cell migration and invasion are repressed by overexpressing miR-144. Cell migration (A and $\mathbf{B})$ and cell invasion (C and $\mathbf{D})$ of A549 cells interfere with miR-144, detected by scratch test (A and $\mathbf{B})$ and transwell assay (C and $\mathbf{D})$. A: Dashed lines denote the edge of areas without cells, and the distance between two dashed white lines is the scratch width. The measurement data were analyzed by one-way analysis of variance. The experiment was repeated three times. Data are expressed as means \pm SD (C and $\mathbf{D})$. ${ }^{*} P<0.05$ versus A549 cells without transfection; ${ }^{\dagger} P<0.05$ versus A549 cells transfected with siRNA negative control (si-NC) or NC plasmids. Scale bars $=50 \mu \mathrm{m}$ (B). Original magnification: $\times 40($ A); $\times 200(B)$.

the proportion at $\mathrm{G}_{0} / \mathrm{G}_{1}$ phase, and cell apoptosis rate in A549 cells were reduced, whereas the expression of HOXA10 and Bcl-2 and proportion at S phase in A549 cells were increased. Meanwhile, A549 cells transfected with si-LINC00466 exhibited the opposite results $(P<0.05)$. In addition, in the A549 cells after the treatment of $m i R-144$ mimic or si-HOXA10, the expression of Bcl-2-associated $\mathrm{X}$ protein, the proportion at $\mathrm{G}_{0} / \mathrm{G}_{1}$ phase, and cell apoptosis rate were higher, whereas the expression of HOXA10 and $\mathrm{Bcl}-2$ and proportion at $\mathrm{S}$ phase were lower $(P<0.05)$. To elaborate, the aforementioned experiments were conducted in XWLC-05 cells again, the results of which were consistent with A549 cells (Supplemental Figures S4, S5, and S6). Thus, silencing LINCO0466 or HOXA10 or even just overexpressing miR-144 enhanced apoptosis of lung adenocarcinoma cells.

\section{Silencing LINCO0466 and HOXA10 or Overexpressing} miR-144 Arrests Cell Migration and Invasion in Lung Adenocarcinoma

The effects of LINC00466, HOXA10, and miR-144 in lung adenocarcinoma A549 cells were found through scratch test and transwell assay. Overexpressing LINCO0466 stimulated cell migration and invasion; however, silencing LINC00466 in A549 cells also inhibited cell migration and invasion 
A
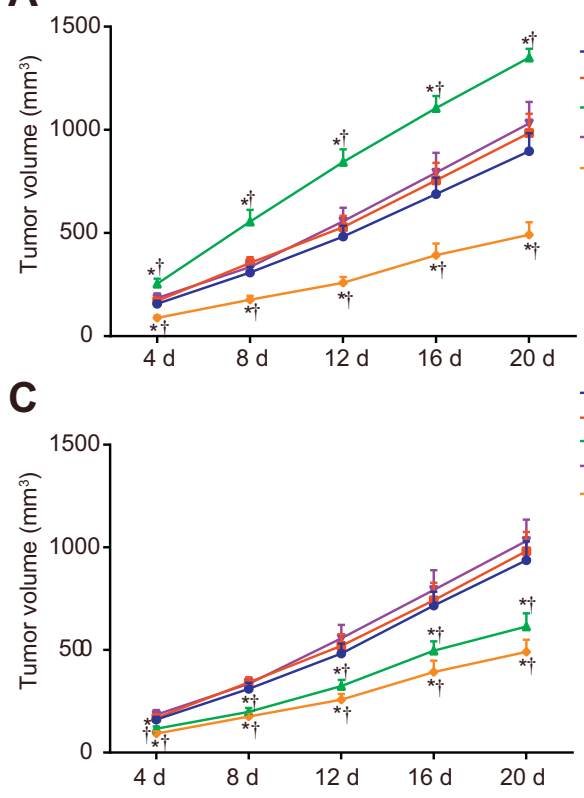

E

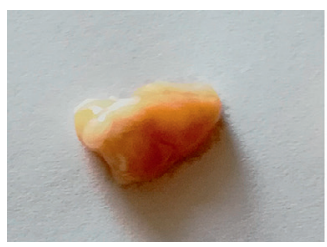

F

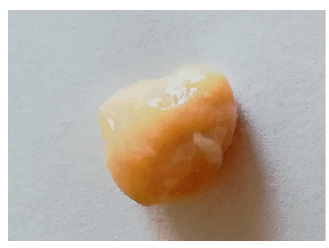

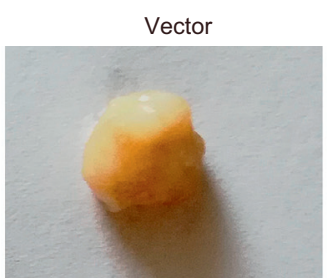

NC

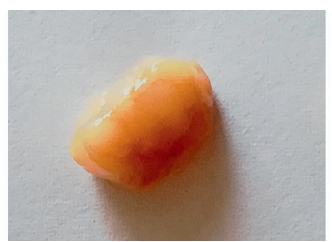

B

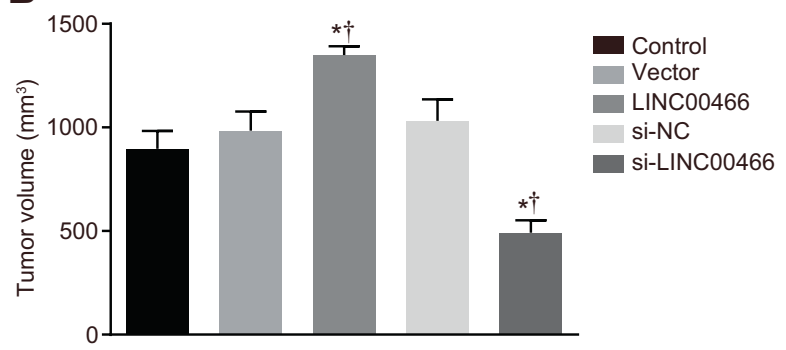

D

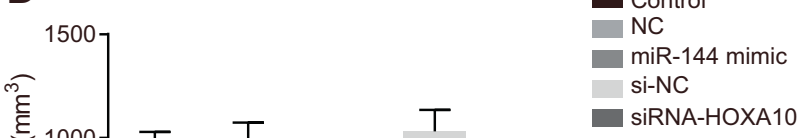

- Control

$=$ NC

$\rightarrow$ si-NC

$\rightarrow$ siRNA-HOXA10

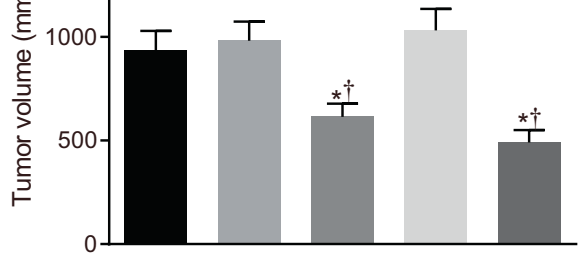

LINC00466

si-NC

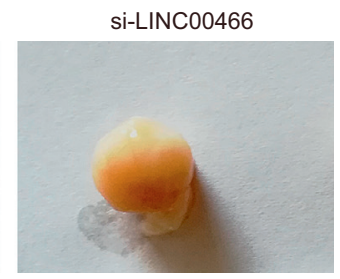

miR-144 mimic
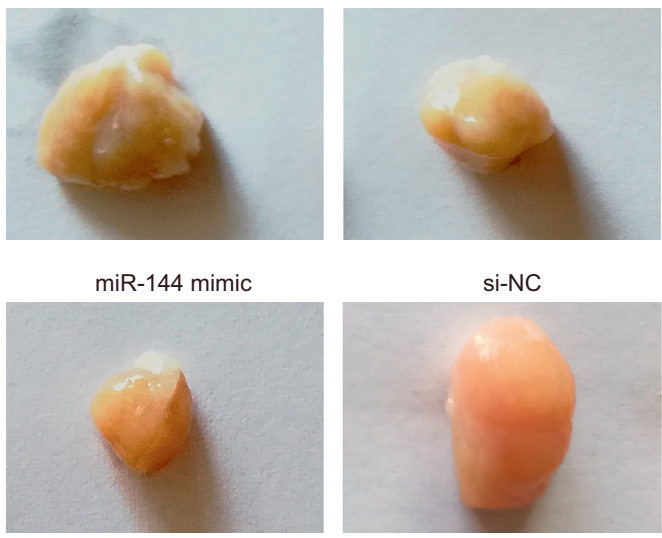

si-NC

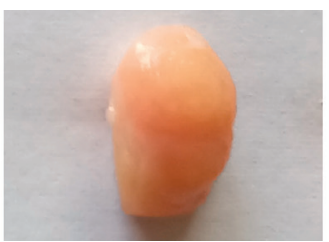

SiRNA-HOXA10

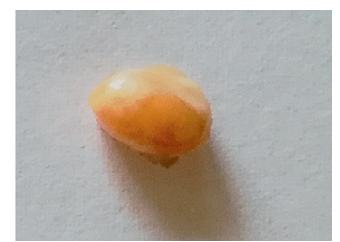

Figure 14 Tumor formation and growth are inhibited by silencing LINC00466 or overexpressing miR-144. A-F: Tumor volume of A549 cells interferes with LINC00466 (A and B) and miR-144 (C and D), detected by tumor formation in nude mice. Tumor growth of A549 cells interferes with LINC00466 (E) and miR-144 (F), detected by tumor formation in nude mice. A and C: Data at different time points were analyzed by repeated analysis of variance. B and D: Data at different time points were analyzed by one-way analysis of variance. The experiment was repeated three times. Data are expressed as mean \pm SD (B and $\mathbf{D}$ ). ${ }^{*} P<0.05$ versus the nude mice injected with A549 cells without transfection; ${ }^{\dagger} P<0.05$ versus the nude mice injected with A549 cells transfected with blank vector, siRNA negative control (si-NC), or NC plasmids.

$(P<0.05)$ (Figure 12). In addition, A549 cells after miR-144 mimic treatment or si-HOXA10 treatment showed repressed cell migration and invasion $(P<0.05)$ (Figure 13). Furthermore, the results of XWLC-05 cells coincided with A549 cells (Supplemental Figures S7 and S8). Therefore, absence of LINC00466 and HOXA10 or presence of $m i R-144$ repressed lung adenocarcinoma cell migration and invasion.

\section{Silencing of LINCO0466 and HOXA10 or Elevation of} miR-144 Inhibits Tumor Formation and Growth in Nude Mice

Consequently, the functions of LINC00466, HOXA10, and miR-144 in lung adenocarcinoma tumor formation and growth were validated in nude mice (Figure 14). Overexpressing LINC00466 promoted tumor growth, whereas silencing LINC00466 lowered the chances of tumor growth $(P<0.05)$. Meanwhile, nude mice after the treatment of $m i R$ 144 mimic or si-HOXA10 presented repressed tumor growth $(P<0.05)$. Thereby, depletion of LINC00466 and HOXA1O or elevation of miR-144 could induce inhibition of tumor formation and growth of lung adenocarcinoma in vivo.

\section{Discussion}

Lung adenocarcinoma is a malignant tumor known to have high mortality. Special treatment for lung adenocarcinoma is urgently needed. ${ }^{3,5}$ LncRNAs were indicated to be critical regulators in cellular development and human diseases 


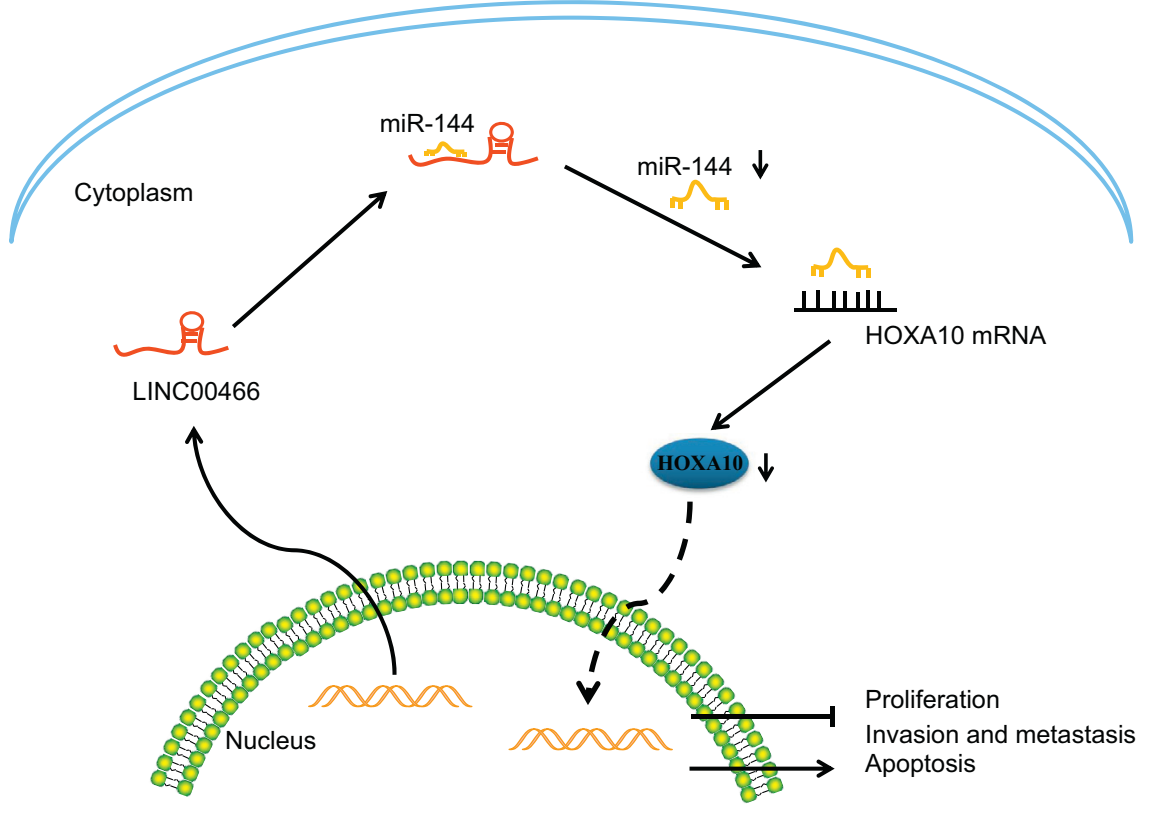

Figure 15 The mechanism of LINC00466 regulating proliferation, invasion, apoptosis, and migration in lung adenocarcinoma A549 cells. High expression of LINCO0466 is found in lung adenocarcinoma. Down-regulation of LINC00466 can enhance the expression of miR-144 by reducing the binding with miR-144, which would further inhibit the expression of HOXA1O and, therefore, suppress migration, proliferation, and invasion and promote apoptosis of lung adenocarcinoma cells.

through the modulation of gene expression. ${ }^{23}$ In this experiment, the main purpose was to verify the mechanism of LINC00466 in lung adenocarcinoma progression.

In lung adenocarcinoma, LINC00466 and HOXA10 expression was found to be elevated and miR-144 expression was found to be depleted. A few lncRNAs were highly expressed in lung adenocarcinoma, including LINC00152, LINC01207, and LINC01614, which advanced tumor progression. $^{24-26}$ Lung cancers correlate with frequent and substantial changes in $H O X$ gene expression. ${ }^{27}$ Several $H O X$ family members, such as $H O X B 9, H O X A 9$, and HOXA10, displayed high expression in lung cancer tissues and cell lines, which functioned as negative prognostic factors in lung cancer. $^{27}$ Consistent with this study, HOXA10 was also highly expressed in human lung tumor tissues and cells. This has the potential to promote lung cancer development. ${ }^{28}$ HOXA10 antisense RNA was also up-regulated in lung adenocarcinoma. ${ }^{29}$ Moreover, a study also indicated that relative to paired adjacent normal tissues, lung cancer tissues exhibited a lower $m i R-144$ expression. $^{30}$ Furthermore, $m i R-144$ was down-regulated in whole blood in lung adenocarcinoma ${ }^{31}$ as a positive regulator.

Another fundamental discovery was that LINC00466 has the ability to bind to miR-144, which directly targeted HOXA10. LINC00466 overexpression inhibited miR-144 expression and promoted $H O X A 10$ expression. A study that investigated the IncRNA-miRNA-mRNA network in breast cancer showed that LINC00466 may down-regulate $m i R$ 144 in breast cancer. ${ }^{32}$ HOXA10 is targeted by several miRNAs in different cancers: HOXA10 is targeted by miR$135 \mathrm{a}$ in epithelial ovarian cancer, by $m i R-494$ in oral cancer, and by $m i R-218$ in hepatocellular carcinoma. ${ }^{22,33,34}$
Furthermore, silencing LINC00466 or HOXA10 or overexpressing $m i R-144$ inhibited tumorigenesis, cell proliferation, migration, and invasion and promoted cell apoptosis of lung adenocarcinoma cells. LINC00152 and LINC01207 were highly expressed in lung adenocarcinoma, and knockdown of LINC00152 or LINC01207 suppressed cell growth and induced cell apoptosis in lung adenocarcinoma. ${ }^{25,35}$ LncRNA HOTAIR was a significant factor in lung cancer diagnosis and treatment, which had the ability to promote survival, invasion, proliferation, metastasis, and drug resistance of lung cancer cells. ${ }^{36}$ Overexpression of $m i R-144$ was also capable of inducing cell apoptosis and inhibiting cell growth and tumorigenesis in non-small-cell lung carcinoma through down-regulation of zinc finger $\mathrm{X}$ chromosomal. ${ }^{37}$ Another study also revealed that $m i R-144$ $5 p$ promotes the radiosensitivity of non-small-cell lung cancer cells via targeting activating transcription factor $2 .^{38}$ Silencing HOXA10-AS was found to attenuate lung adenocarcinoma progression through repression of proliferation, migration, and epithelial-mesenchymal transition as well as promotion of apoptosis in lung adenocarcinoma cells. ${ }^{29}$ Therefore, LINC00466, HOXA10, or miR-144 could be considered as potential therapeutic target for lung adenocarcinoma.

LINC00466 knockdown may exhibit an attenuated ability on the HOXA10 expression by promoting $\mathrm{miR}-144$ expression, which regulates cell proliferation, invasion, migration, and tumorigenicity in lung adenocarcinoma (Figure 15). This present study provides evidence for the cross talk between miR-144, LINC00466, and HOXA10, which sheds new light on the treatment of lung adenocarcinoma. 


\section{Acknowledgments}

We thank the reviewers for helpful comments on this article.

\section{Supplemental Data}

Supplemental material for this article can be found at http://doi.org/10.1016/j.ajpath.2019.06.014.

\section{References}

1. Xu CH, Yu LK, Hao KK: Serum YKL-40 level is associated with the chemotherapy response and prognosis of patients with small cell lung cancer. PLoS One 2014, 9:e96384

2. Rodriguez EF, Monaco SE, Dacic S: Cytologic subtyping of lung adenocarcinoma by using the proposed International Association for the Study of Lung Cancer/American Thoracic Society/European Respiratory Society (IASLC/ATS/ERS) adenocarcinoma classification. Cancer Cytopathol 2013, 121:629-637

3. Liu J, Yang XY, Shi WJ: Identifying differentially expressed genes and pathways in two types of non-small cell lung cancer: adenocarcinoma and squamous cell carcinoma. Genet Mol Res 2014, 13:95-102

4. Campbell JD, Alexandrov A, Kim J, Wala J, Berger AH, Pedamallu CS, Shukla SA, Guo G, Brooks AN, Murray BA, Imielinski M, Hu X, Ling S, Akbani R, Rosenberg M, Cibulskis C, Ramachandran A, Collisson EA, Kwiatkowski DJ, Lawrence MS, Weinstein JN, Verhaak RG, Wu CJ, Hammerman PS, Cherniack AD, Getz G; Cancer Genome Atlas Research Network, Artyomov MN, Schreiber R, Govindan R, Meyerson M: Distinct patterns of somatic genome alterations in lung adenocarcinomas and squamous cell carcinomas. Nat Genet 2016, 48:607-616

5. Cancer Genome Atlas Research Network: Comprehensive molecular profiling of lung adenocarcinoma. Nature 2014, 511:543-550

6. Ding L, Getz G, Wheeler DA, Mardis ER, McLellan MD, Cibulskis K, et al: Somatic mutations affect key pathways in lung adenocarcinoma. Nature 2008, 455:1069-1075

7. Gong WJ, Yin JY, Li XP, Fang C, Xiao D, Zhang W, Zhou HH, Li X, Liu ZQ: Association of well-characterized lung cancer lncRNA polymorphisms with lung cancer susceptibility and platinum-based chemotherapy response. Tumour Biol 2016, 37:8349-8358

8. Dong HX, Wang R, Jin XY, Zeng J, Pan J: LncRNA DGCR5 promotes lung adenocarcinoma (LUAD) progression via inhibiting hsamir-22-3p. J Cell Physiol 2018, 233:4126-4136

9. Salas LA, Johnson KC, Koestler DC, O'Sullivan DE, Christensen BC: Integrative epigenetic and genetic pan-cancer somatic alteration portraits. Epigenetics 2017, 12:561-574

10. Huang Y, Chang Z, Li X, Liang S, Yi Y, Wu L: Integrated multifactor analysis explores core dysfunctional modules in autism spectrum disorder. Int J Biol Sci 2018, 14:811-818

11. Iaboni M, Russo V, Fontanella R, Roscigno G, Fiore D, Donnarumma E, Esposito CL, Quintavalle C, Giangrande PH, de Franciscis V, Condorelli G: Aptamer-miRNA-212 conjugate sensitizes NSCLC cells to TRAIL. Mol Ther Nucleic Acids 2016, 5:e289

12. Wang XC, Tian LL, Jiang XY, Wang YY, Li DG, She Y, Chang JH, Meng AM: The expression and function of miRNA-451 in non-small cell lung cancer. Cancer Lett 2011, 311:203-209

13. Yin Z, Xu M, Li P: miRNA-221 acts as an oncogenic role by directly targeting TIMP2 in non-small-cell lung carcinoma. Gene 2017, 620: $46-53$

14. Iwaya T, Yokobori T, Nishida N, Kogo R, Sudo T, Tanaka F, Shibata K, Sawada G, Takahashi Y, Ishibashi M, Wakabayashi G, Mori M, Mimori K: Downregulation of miR-144 is associated with colorectal cancer progression via activation of mTOR signaling pathway. Carcinogenesis 2012, 33:2391-2397
15. Akiyoshi S, Fukagawa T, Ueo H, Ishibashi M, Takahashi Y, Fabbri M, Sasako M, Maehara Y, Mimori K, Mori M: Clinical significance of miR-144-ZFX axis in disseminated tumour cells in bone marrow in gastric cancer cases. Br J Cancer 2012, 107: $1345-1353$

16. Cao T, Li H, Hu Y, Ma D, Cai X: miR-144 suppresses the proliferation and metastasis of hepatocellular carcinoma by targeting E2F3. Tumour Biol 2014, 35:10759-10764

17. Pan HL, Wen ZS, Huang YC, Cheng X, Wang GZ, Zhou YC, Wang ZY, Guo YQ, Cao Y, Zhou GB: Down-regulation of microRNA144 in air pollution-related lung cancer. Sci Rep 2015, 5:14331

18. Han Y, Lu S, Wen YG, Yu FD, Zhu XW, Qiu GQ, Tang HM, Peng ZH, Zhou CZ: Overexpression of HOXA10 promotes gastric cancer cells proliferation and $\mathrm{HOXA10}(+) / \mathrm{CD} 44(+)$ is potential prognostic biomarker for gastric cancer. Eur J Cell Biol 2015, 94:642-652

19. Li B, Cao X, Weng C, Wu Y, Fang X, Zhang X, Liu G: HoxA10 induces proliferation in human prostate carcinoma PC-3 cell line. Cell Biochem Biophys 2014, 70:1363-1368

20. Sun S, Su C, Zhu Y, Li H, Liu N, Xu T, Sun C, Lv Y: MicroRNA-544a regulates migration and invasion in colorectal cancer cells via regulation of homeobox A10. Dig Dis Sci 2016, 61: $2535-2544$

21. Liu J, Jiang Y, Wan Y, Zhou S, Thapa S, Cheng W: MicroRNA665 suppresses the growth and migration of ovarian cancer cells by targeting HOXA10. Mol Med Rep 2018, 18:2661-2668

22. Liborio-Kimura TN, Jung HM, Chan EK: miR-494 represses HOXA10 expression and inhibits cell proliferation in oral cancer. Oral Oncol 2015, 51:151-157

23. Zhao L, Sun H, Kong H, Chen Z, Chen B, Zhou M: The LncrnaTUG1/EZH2 axis promotes pancreatic cancer cell proliferation, migration and EMT phenotype formation through sponging Mir-382. Cell Physiol Biochem 2017, 42:2145-2158

24. Zhang PP, Wang YQ, Weng WW, Nie W, Wu Y, Deng Y, Wei P, Xu MD, Wang CF: Linc00152 promotes cancer cell proliferation and invasion and predicts poor prognosis in lung adenocarcinoma. J Cancer 2017, 8:2042-2050

25. Wang G, Chen H, Liu J: The long noncoding RNA LINC01207 promotes proliferation of lung adenocarcinoma. Am J Cancer Res 2015, 5:3162-3173

26. Liu AN, Qu HJ, Yu CY, Sun P: Knockdown of LINC01614 inhibits lung adenocarcinoma cell progression by up-regulating miR-217 and down-regulating FOXP1. J Cell Mol Med 2018, 22:4034-4044

27. Calvo R, West J, Franklin W, Erickson P, Bemis L, Li E, Helfrich B, Bunn P, Roche J, Brambilla E, Rosell R, Gemmill RM, Drabkin HA: Altered HOX and WNT7A expression in human lung cancer. Proc Natl Acad Sci U S A 2000, 97:12776-12781

28. Ludovini V, Bianconi F, Siggillino A, Piobbico D, Vannucci J, Metro G, Chiari R, Bellezza G, Puma F, Della Fazia MA, Servillo G, Crino L: Gene identification for risk of relapse in stage I lung adenocarcinoma patients: a combined methodology of gene expression profiling and computational gene network analysis. Oncotarget 2016, 7:30561-30574

29. Sheng K, Lu J, Zhao H: ELK1-induced upregulation of IncRNA HOXA10-AS promotes lung adenocarcinoma progression by increasing Wnt/beta-catenin signaling. Biochem Biophys Res Commun 2018, 501:612-618

30. Chen S, Li P, Li J, Wang Y, Du Y, Chen X, Zang W, Wang H, Chu H, Zhao G, Zhang G: MiR-144 inhibits proliferation and induces apoptosis and autophagy in lung cancer cells by targeting TIGAR. Cell Physiol Biochem 2015, 35:997-1007

31. Patnaik SK, Yendamuri S, Kannisto E, Kucharczuk JC, Singhal S, Vachani A: MicroRNA expression profiles of whole blood in lung adenocarcinoma. PLoS One 2012, 7:e46045

32. Fan CN, Ma L, Liu N: Systematic analysis of lncRNA-miRNA-mRNA competing endogenous RNA network identifies four-lncRNA signature as a prognostic biomarker for breast cancer. J Transl Med 2018, $16: 264$ 
33. Tang W, Jiang Y, Mu X, Xu L, Cheng W, Wang X: MiR-135a functions as a tumor suppressor in epithelial ovarian cancer and regulates HOXA10 expression. Cell Signal 2014, 26:1420-1426

34. Xiao ZD, Jiao CY, Huang HT, He LJ, Zhao JJ, Lu ZY, Liu LX: miR218 modulate hepatocellular carcinoma cell proliferation through PTEN/AKT/PI3K pathway and HoxA10. Int J Clin Exp Pathol 2014, 7:4039-4044

35. Chen QN, Chen X, Chen ZY, Nie FQ, Wei CC, Ma HW Wan L, Yan S, Ren SN, Wang ZX: Long intergenic non-coding RNA 00152 promotes lung adenocarcinoma proliferation via interacting with EZH2 and repressing IL24 expression. Mol Cancer 2017, 16:17

36. Loewen G, Jayawickramarajah J, Zhuo Y, Shan B: Functions of lncRNA HOTAIR in lung cancer. J Hematol Oncol 2014, 7:90

37. Zha W, Cao L, Shen Y, Huang M: Roles of Mir-144-ZFX pathway in growth regulation of non-small-cell lung cancer. PLoS One 2013, 8: e74175

38. Song L, Peng L, Hua S, Li X, Ma L, Jie J, Chen D, Wang Y, Li D: miR-144-5p enhances the radiosensitivity of non-small-cell lung cancer cells via targeting ATF2. Biomed Res Int 2018, 2018:5109497 